Subscriber access provided by Caltech Library

\title{
Article
}

\section{Size-Matched Radical Multivalency}

Mark C. Lipke, Tao Cheng, Yilei Wu, Hasan Arslan, Hai Xiao, Michael R. Wasielewski, William A. Goddard, and J. Fraser Stoddart

J. Am. Chem. Soc., Just Accepted Manuscript • DOI: 10.1021/jacs.6b09892 • Publication Date (Web): 07 Feb 2017

Downloaded from http://pubs.acs.org on February 10, 2017

\section{Just Accepted}

"Just Accepted" manuscripts have been peer-reviewed and accepted for publication. They are posted online prior to technical editing, formatting for publication and author proofing. The American Chemical Society provides "Just Accepted" as a free service to the research community to expedite the dissemination of scientific material as soon as possible after acceptance. "Just Accepted" manuscripts appear in full in PDF format accompanied by an HTML abstract. "Just Accepted" manuscripts have been fully peer reviewed, but should not be considered the official version of record. They are accessible to all readers and citable by the Digital Object Identifier (DOI®). "Just Accepted" is an optional service offered to authors. Therefore, the "Just Accepted" Web site may not include all articles that will be published in the journal. After a manuscript is technically edited and formatted, it will be removed from the "Just Accepted" Web site and published as an ASAP article. Note that technical editing may introduce minor changes to the manuscript text and/or graphics which could affect content, and all legal disclaimers and ethical guidelines that apply to the journal pertain. ACS cannot be held responsible for errors or consequences arising from the use of information contained in these "Just Accepted" manuscripts. 


\title{
Size-Matched Radical Multivalency
}

\author{
Mark C. Lipke, ${ }^{1}$ Tao Cheng, ${ }^{2}$ Yilei Wu, ${ }^{1}$ Hasan Arslan, ${ }^{1}$ Hai Xiao, ${ }^{2}$ Michael R. Wasielewski, ${ }^{1}$ \\ William A. Goddard III, ${ }^{2}$ J. Fraser Stoddart ${ }^{1 *}$ \\ ${ }^{1}$ Department of Chemistry, Northwestern University, 2145 Sheridan Road, Evanston, \\ IL 60208 (USA) \\ ${ }^{2}$ Materials and Process Simulation Center, , California Institute of Technology, 1200 California \\ Blvd, Pasadena, CA 91125 (USA) \\ *E-mail: stoddart@northwestern.edu
}

\section{MAIN TEXT}

Professor J. Fraser Stoddart

Department of Chemistry

Northwestern University

2145 Sheridan Road

Evanston, IL 60208 (USA)

Email: stoddart@northwestern.edu 
ABSTRACT: Persistent $\pi$-radicals such as $\mathbf{M V}^{+\bullet}$ (MV refers to methyl viologen, i.e., $N, N^{\prime}-$ dimethyl-4,4'-bipyridinum) engage in weak radical-radical interactions. This phenomenon has been utilized recently in supramolecular chemistry with the discovery that $\mathbf{M V}^{\mathbf{+}^{\bullet}}$ and

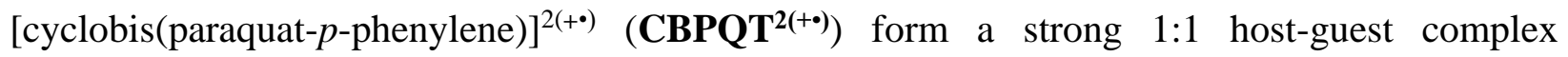
$[\text { CBPQT } \subset \text { MV] }]^{\mathbf{3}(\bullet)}$. In this full paper, we describe the extension of radical-pairing-based molecular recognition to a larger, square-shaped diradical host, [cyclobis(paraquat-4,4'biphenylene $)]^{2\left(+^{\bullet}\right)}\left(\mathbf{M S}^{\mathbf{2}(+\bullet)}\right)$. This molecular square was evaluated for its ability to bind an isomeric series of possible diradical cyclophane guests, which consist of two radical viologen units that are linked by two ortho-, meta-, or para-xylylene bridges to provide different spacing between the planar radicals. UV-Vis-NIR Measurements reveal that only the $m$-xylylene-linked

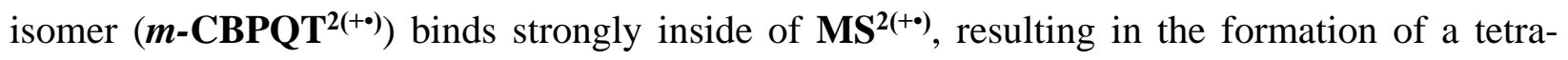

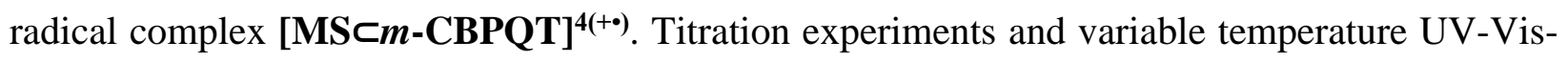
NIR and EPR spectroscopic data indicate that, relative to the smaller trisradical complex $[\mathbf{C B P Q T} \subset \mathbf{M V}]^{3(+\bullet)}$, the new host-guest complex forms with a more favorable enthalpy change that is offset by a greater entropic penalty. As a result, the association constant $\left(K_{\mathrm{a}}=(1.12+/-0.08) \times 10^{5} \mathrm{M}^{-1}\right)$ for $[\mathrm{MS} \subset \mathrm{m}-\mathrm{CBPQT}]^{4(+\bullet)}$ is similar to that previously determined

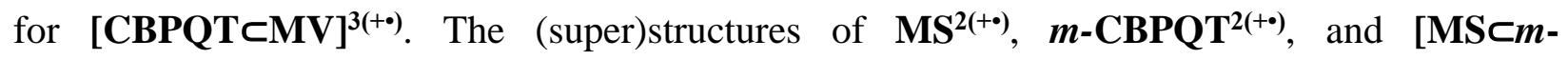
CBPQT $]^{4(+\bullet)}$ were examined by single-crystal X-ray diffraction measurements and DFT calculations. The solid-state and computational structural analyses reveal that $\boldsymbol{m}$-CBPQT $\mathbf{C}^{\mathbf{2 ( + \bullet})}$ is ideally sized to bind inside of $\mathbf{M S}^{\mathbf{2 ( + \bullet})}$. The solid-state superstructures also indicate that localized radical-radical interactions in $\boldsymbol{m}$-CBPQT $\mathbf{T}^{(+\bullet)}$ and $[\mathbf{M S} \subset \boldsymbol{m} \text {-CBPQT }]^{4(+\bullet)}$ disrupt the extended radical-pairing interactions that are common in crystals of other viologen radical cations. Lastly, the formation of $[\mathrm{MS} \subset \boldsymbol{m}-\mathrm{CBPQT}]^{\mathbf{4 ( + \bullet )}}$ was probed by cyclic voltammetry, demonstrating that the radical states of the cyclophanes are stabilized by the radical-pairing interactions. 


\section{- INTRODUCTION}

The study of synthetic hosts for guest recognition, which was initiated with the synthesis of crown ethers that bind Group IA and IIA metal cations, ${ }^{1}$ has subsequently undergone expansion to incorporate the investigation of inclusion complexes based on a diverse array of molecular recognition motifs. ${ }^{2-7}$ Complexes have been formed using electrostatic attraction, ${ }^{3}$ the hydrophobic effect, ${ }^{4} \pi-\pi$ stacking, ${ }^{5}$ hydrogen bonding, ${ }^{6}$ and numerous other noncovalent bonding interactions. ${ }^{2}$ A noteworthy feature of many recognition motifs is the importance of size-complementarity between the host and the guest, as noted early on in size-matched crown ethers and cations. ${ }^{1,7}$ Other size-based binding recognition phenomena include Rebek's 55percent rule ${ }^{8}$ for the inclusion of guests inside hydrophobic capsules, and the necessity for a 3.2 $3.5 \AA$ spacing between the $\pi$-surfaces of donor-acceptor $\pi$ - $\pi$ stacks. ${ }^{9}$ This latter consideration has been a defining feature of the tetracationic host, cyclobis(paraquat- $p$-phenylene) ${ }^{10}\left(\mathbf{C B P Q T}^{\mathbf{4}}\right)$, which has two electron-deficient viologen units - i.e., 4,4'-bipyridinium dications - that are ideally spaced (Scheme 1, upper left) for interaction with planar, electron-rich aromatic guests such as tetrathiafulvene ${ }^{10 c}$ (TTF). More recently, the spacing of viologen units has been found ${ }^{11}$ to be ideal (Scheme 1, upper right) for the diradical dication $\mathbf{C B P Q T}^{\mathbf{2}(+\bullet)}$ to bind the methyl viologen radical cation $\left(\mathbf{M V}^{+\bullet}\right)$ as a unique tricationic trisradical complex held together by

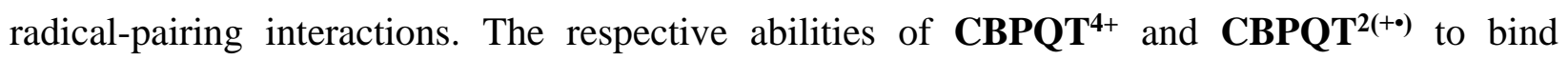
aromatic and $\pi$-radical guests has made this redox-active cyclophane one of the most studied of supramolecular hosts. ${ }^{2 \mathrm{~m}, 1,5 \mathrm{~b}, 12}$ Recognition motifs of these types have been used to template the formation of a wide variety of mechanically interlocked molecules ${ }^{13}$ (MIMs) and artificial molecular machines ${ }^{14}$ (AMMs). 
Despite the long history of $\mathbf{C B P Q T}^{4+}$, it is only recently that much attention has been given to size-homologues of this host, ${ }^{12,15}$ a situation which stands in contrast to other common macrocyclic hosts - e.g., cucurbiturils, ${ }^{16}$ cyclodextrins, ${ }^{17}$ and crown ethers ${ }^{1,7}$ — for which many differently sized variants have been investigated. Early efforts at expanding the CBPQT ${ }^{\mathbf{4}}$ motif include the synthesis of the square-shaped tetracationic cyclobis(paraquat-4,4'-biphenylene) ${ }^{18}$ $\left(\mathbf{M S}^{\mathbf{4}}\right)$, which provides a significantly increased separation between its viologen units. This increase creates enough space to form a 1:1 complex with ferrocene ${ }^{18}$ or to host planar aromatic guests in a 1:2 host-guest ratio, ${ }^{19}$ despite the fact that both types of interactions are weak in the absence of supporting [C-H---O] hydrogen bonding interactions. ${ }^{18,19 \mathrm{c}}$ Nevertheless, these 1:2 complexes have been useful for templating the formation of [3]catenanes, ${ }^{19 a, b}$ [3] rotacatenanes, ${ }^{20}$ and higher order oligocatenanes. ${ }^{21}$ More recent efforts efforts ${ }^{12,15}$ to expand the $\mathbf{C B P Q T}^{\mathbf{4}}$ host have focused primarily on extending the electron poor $\pi$-surface in order to accommodate larger two-dimensional guests along with those that deviate only slightly from planarity, e.g., helicene, corannulene. These two-dimensionally extended variants of $\mathbf{C B P Q T}^{\mathbf{4 +}}$ now abound, while in contrast, only one recent study ${ }^{15 e}$ addresses the binding of a three-dimensional guest, namely $\mathrm{C}_{60}$, by a larger homologue of $\mathbf{C B P Q T}^{4+}$.

Investigations of expanded homologues of $\mathbf{C B P Q T}^{\mathbf{4}}$ have so far overlooked possible radicalbased host-guest chemistry of the reduced states of these cyclophanes. As a result, the small tricationic trisradical $[\mathbf{C B P Q T} \subset \mathbf{M V}]^{\mathbf{3 ( + \bullet})}$, and simple derivatives thereof, ${ }^{22}$ have stood as singular examples of radical-paired host-guest complexes since their introduction more than half a decade ago. In this time period, this interaction has formed the basis of a diverse array of MIMs and AMMs such as multistate redox-actuated switches, ${ }^{23}$ nanopumps, ${ }^{14 \mathrm{~d}}$ and molecular muscles. ${ }^{24}$ The development of additional, larger examples of these radical-based recognition 
motifs could provide routes to increase the sophistication of these molecular arrays and to prepare assemblies with new properties and functions. This full paper describes the examination of radical guests for the square-shaped diradical $\mathbf{M S}^{\mathbf{2}(+\bullet)}$, and the subsequent characterization of a complex featuring the diradical cyclophane cyclobis(paraquat- $m$-phenylene) ${ }^{25}\left(\boldsymbol{m}\right.$-CBPQT $\left.{ }^{2(+\bullet)}\right)$ as the guest (Scheme 1, lower right). Remarkably, this diradical guest is three times the size of the $\mathbf{M V}^{+\bullet}$ guest in $[\mathbf{C B P Q T} \subset \mathbf{M V}]^{\mathbf{3 ( + \bullet}}$, demonstrating that size-complementarity can be incorporated into radical assemblies in much the same manner that size-selective binding characteristics are observed for many classic hosts, e.g., crown ethers, hydrophobic capsules, etc.

\section{- RESULTS AND DISCUSSION}

Assessment of Radical Guests for $\mathbf{M S}^{2(+\bullet)}$. The search for radical guests that form inclusion complexes with the diradical host $\mathbf{M S}^{\mathbf{2 ( + \bullet )}}$ drew inspiration from investigations on the binding of neutral electron-rich guests in the tetracationic $\mathbf{M S}^{\mathbf{4 +}}$ oxidation state of the molecular square. These previous studies revealed that this square is appropriately proportioned to bind two aromatic groups stacked on top of each other, either in the form of a 1:2 complex ${ }^{19}$ $[\mathbf{M S c 2 T T F}]^{4+}$ or involving a single guest in which the two aromatic planes are inherently stacked together, as in ferrocene. ${ }^{18}$ It was not, however, immediately apparent how these considerations would manifest themselves in radical-based recognition chemistry. It seemed intuitive that $\mathbf{M S}^{\mathbf{2}(+\bullet)}$ could possibly host a three-dimensional diradical guest or two planar monoradical guests, but it was not clear what the ideal arrangement (co-conformation) would be for the two guest radicals. For example, it was unclear if the ideal binding motif would involve a continuous interaction of four radicals - i.e., with approximately equidistant spacing between the $\pi$-radical planes — or if a relatively large spacing between the radical planes of the guest(s) 
would be enforced by a preference for two discrete radical-radical interactions with the two radical viologen recognition sites of the square. In order to evaluate these possibilities, several viologen radical guests were examined for their ability to bind within $\mathbf{M S}^{\mathbf{2}(+\bullet)}$. The results of this examination are summarized in Scheme 2.

Three isomers of $\mathbf{C B P Q T}^{\mathbf{2}(+\bullet)}$ were assessed as possible diradical guests. These isomers vary with respect to the connectivity — namely ortho, meta, or para — of the xylylene linkers employed as spacers for the two viologen units. These cyclophanes were readily prepared following established procedures, ${ }^{10,25}$ and reduced to the diradical state using zinc dust as a convenient reductant. ${ }^{11,25}$ The $\boldsymbol{o}$-xylylene-based derivative $\boldsymbol{o}$-CBPQT ${ }^{\mathbf{2}(+\bullet)}$ has the closest spacing of the viologen radicals, such that there is very strong intramolecular pairing of the two free electrons. This latter feature is evident from a characteristic ${ }^{25}$ intense near-IR absorption band $\left(\lambda_{\max }=838 \mathrm{~nm}\right)$ in the UV-Vis-NIR spectrum of $\boldsymbol{o}$-CBPQT ${ }^{2(+\bullet)}(1 \mathrm{mM}$ in MeCN$)$. The intensity of this absorption remains essentially unchanged when an equimolar amount of $\mathbf{M S} \mathbf{S}^{\mathbf{2}(+)}$ is added. The spectrum of the mixed solution does, however, display a weak new NIR absorption band that overlaps partially with that of $\boldsymbol{o}$-CBPQT ${ }^{2(+\bullet)}$, but which extends to longer wavelengths. See Supporting Information. These observations suggest that $\boldsymbol{o}-\mathbf{C B P Q T}^{\mathbf{2}(+\bullet)}$ forms a weakly bound complex with $\mathbf{M S}^{2(+\bullet)}$. Building upon these encouraging results, the more widely spaced isomer $\boldsymbol{m}$-CBPQT ${ }^{2(+\bullet)}$ was found to bind much more strongly inside $\mathbf{M S}^{2(+\bullet)}$ as evidenced by an intense new NIR absorption band $\left(\lambda_{\max }=941 \mathrm{~nm}\right.$, Figure 1) that is absent from the spectra of either individual diradical. This strong binding affinity of $\boldsymbol{m}$-CBPQT $\mathbf{T}^{\mathbf{2 ( + \bullet}}$ does not extend to the more

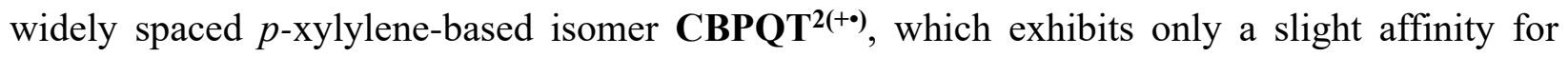
binding inside $\mathbf{M S}^{\mathbf{2 ( + \bullet}}$. Notably, the very weak NIR absorption band $\left(\lambda_{\max }=1103 \mathrm{~nm}\right)$ observed 
for $[\text { MSсCBPQT }]^{4(+\bullet)}$ increases slightly after $24 \mathrm{~h}$, suggesting that the kinetics associated with the formation of this complex are slow. Presumably the $\mathbf{C B P Q T}^{\mathbf{2 ( + \bullet}}$ isomer is too large, from both a thermodynamic and kinetic perspective, to serve as an effective guest, while the $m$ xylylene-based linker in $\boldsymbol{m}$-CBPQT $\mathbf{T}^{\mathbf{2}+\bullet)}$ provides just the right spacing for rapid formation of a strong interaction with the inside of the square.

In light of this knowledge, it seemed possible that $\mathbf{M S}^{\mathbf{2 ( + \bullet )}}$ might bind two $\mathbf{M V}^{+\bullet}$ guests much in the same way as the similarly sized host, cucurbit[8]uril, promotes ${ }^{26}$ the dimerization of two $\mathbf{M V}^{+\bullet}$ radical cations within its cavity. Notably, however, $\mathbf{M V}^{+\bullet}$ shows very little affinity for binding inside $\mathbf{M S}^{\mathbf{2}(+)}$, as evident from the near absence of an NIR absorption band in the UVVis-NIR spectrum of a 1:2 molar ratio solution of the diradical host $(0.5 \mathrm{mM})$ and the monoradical guest $(1.0 \mathrm{mM})$ in $\mathrm{MeCN}$. A low intensity absorption at $\lambda_{\max }=889 \mathrm{~nm}$ is, however, evident, and is nearly tripled in its intensity (from $\mathrm{Abs}=0.089$ to $\mathrm{Abs}=0.24,2 \mathrm{~mm}$ path) when the concentration of $\mathbf{M V}^{+\bullet}$ is increased to $2.0 \mathrm{mM}$. The low intensity of this absorption band makes it difficult to investigate this host-guest interaction, particularly since the weak selfassociations of $\mathbf{M V}^{+\bullet}$ and $\mathbf{M S}^{\mathbf{2 ( + \bullet})}$ also contribute to the NIR-absorptions in this region. The contributions from these dimerizations can, however, be compensated at relatively low concentrations of each viologen species. A Job plot was used to establish a 1:1 association between $\mathbf{M V}^{+\bullet}$ and $\mathbf{M S}^{2(+\bullet)}$. See Supporting Information. The determination of this stoichiometry is notable since this result indicates that a 1:2 host-guest complex does not form even though two $\mathbf{M V}^{+\bullet}$ guests would be free to occupy the ideal spacing within the square to reinforce eachother's binding. In this respect, the behavior of the radical systems contrasts with that of the 
donor-acceptor complexes ${ }^{10 c, d ; 18 b}[\mathbf{C B P Q T} \subset \mathbf{T T F}]^{4+}$ and $[\mathbf{M S} \subset \mathbf{2 T T F}]^{4+}$ in which the two hosts exhibit different stoichiometries when binding the same planar guest.

These preliminary results show that $\mathbf{M S}^{2(+\bullet)}$ exhibits high selectivity in the formation of $[\mathrm{MS} \subset \boldsymbol{m}-\mathbf{C B P Q T}]^{4(+\bullet)}$ relative to the selectivities observed for related hosts-guest systems involving either $\mathbf{M S}^{4+}$ or cucurbit[8]uril. An additional observation that $\mathbf{M V}^{+\bullet}$ and $\boldsymbol{m}$-CBPQT $\mathbf{C}^{2(+\bullet)}$ do not interact means that both the components of the tetraradical complex [MS $\subset$ mCBPQT $]^{4(+\bullet)}$ do not engage in significant interactions with either component of the trisradical $[\mathbf{C B P Q T} \subset \mathbf{M V}]^{3(+\bullet)}$. The pronounced selectivity of these host-guest interactions is remarkable considering the fact that the two complexes are based on the same type of recognition motif.

The apparently strong binding of $\boldsymbol{m}$-CBPQT ${ }^{2(+\bullet)}$ with $\mathbf{M S}^{2(+\bullet)}$ was probed to provide a quantitative assessment of the stoichiometry, binding constant, and thermodynamic parameters associated with the formation of this complex. A Job plot (see Supporting Information) demonstrated 1:1 host-guest stoichiometry, as expected, based on the assumption that the smaller radical cyclophane binds inside of the larger one. The binding constant at $25^{\circ} \mathrm{C}$ in $\mathrm{MeCN}$ was determined by titrations (Figure 2a) that were monitored by the NIR absorption of the complex $[\mathbf{M S} \subset \boldsymbol{m}-\mathbf{C B P Q T}]^{4(+\bullet)}$. The resulting data was fitted to a 1:1 binding isotherm (see Supporting Information) and the average of four titrations produces a $K_{\mathrm{a}}$ value of $(7.9 \pm 1.9) \times 10^{4} \mathrm{M}^{-1}$, which is similar to those $\left(K_{\mathrm{a}}=7.9 \pm 5.5 \times 10^{4} \mathrm{M}^{-1}\right.$ (by UV-Vis), $5.04 \pm 0.63 \times 10^{4} \mathrm{M}^{-1}$ (by ITC) $)^{11 \mathrm{~b}}$ obtained for the trisradical complex $[\mathbf{C B P Q T} \subset \mathbf{M V}]^{3(+\cdot)}$. Thus, the increased radical interactions presumed to be present in the tetraradical $[\mathbf{M S} \subset \boldsymbol{m} \text {-CBPQT }]^{4(+\bullet)}$ must be evenly counterbalanced by factors such as charge-repulsion or entropic penalties that diminish binding. See below for further discussions. 
The relatively high error in the association constant for $[\mathbf{M S} \subset \boldsymbol{m}-\mathbf{C B P Q T}]^{\mathbf{4 ( + \bullet )}}$ determined by titration measurements can be attributed to a number of factors, including - (i) the fact that reduction of $\mathbf{M S}^{4+}$ with $\mathrm{Zn}$ does not produce concentrations of $\mathbf{M S}^{\mathbf{2 ( + \bullet})}$ (determined by UV-Vis spectroscopy) that are consistent as those obtained when reducing other viologen species with $\mathrm{Zn}$. This observation can be attributed to partial over-reduction to the $\mathbf{M S}^{\mathbf{0}}$ oxidation state, which is not expected to be accessible in solution using $\mathrm{Zn}$ as the reductant, yet may be driven by the precipitation of $\mathbf{M S}^{\mathbf{0}}$ owing to its low solubility ${ }^{34}$ in $\mathrm{MeCN}$. The actual concentration of $\mathbf{M S}^{\mathbf{2 ( + \bullet})}$ in the titrant was determined by UV-Vis spectroscopy prior to the titration. If the precipitate of $\mathbf{M S}^{\mathbf{0}}$ is, however, too fine to remove by filtration, its presence might influence the results of the titration. - (ii) the fact that $\mathbf{M S}^{\mathbf{4}}$ has relatively low solubility in $\mathrm{MeCN}$, which limits the concentration of $\mathbf{M S}^{\mathbf{2 ( + \bullet}}$ that can be used to titrate a solution of $\boldsymbol{m}$-CBPQT ${ }^{2(+\bullet)}$. This latter consideration necessitates adding a relatively large volume of the titrant during each run, a practice which might introduce larger errors than normally expected for a strongly bound hostguest complex. It is worthy of note that titrating $\mathbf{M S}^{\mathbf{2 ( + \bullet )}}$ with an excess of $\boldsymbol{m}-\mathbf{C B P Q T} \mathbf{T}^{\mathbf{2}(+\bullet)}$ is not an option since this diradical dication features a non-negligible NIR absorption band in its own right.

Though an unusually large error in the association constant was found by the titrations, these experiments provided consistent values for the molar absorptivity $\left(\varepsilon 941 \mathrm{~nm}=18765 \mathrm{~cm}^{-1} \bullet \mathrm{M}^{-1}\right.$ $\left.\pm 412 \mathrm{~cm}^{-1} \bullet \mathrm{M}^{-1}\right)$ of the NIR band for $[\mathbf{M S} \subset \boldsymbol{m}-\mathbf{C B P Q T}]^{4(+\bullet)}$. This value was used to calculate the binding constant at $298 \mathrm{~K}$ based on the intensities of the NIR absorption bands observed for solutions containing $0.05 \mathrm{mM}$ of each diradical dication. This method provides consistent values for association constants $\left(K_{\mathrm{a}}=(1.12 \pm 0.08) \times 10^{5} \mathrm{M}^{-1}\right.$ from five samples $)$ that are similar to the 
largest $K_{\mathrm{a}}$ value $\left(1.09 \times 10^{5} \mathrm{M}^{-1}\right)$ determined from titrations. A relatively large $K_{\mathrm{a}}$ value of $(1.7 \pm$ 0.25) $\times 10^{5} \mathrm{M}^{-1}$ was also obtained from EPR spectra. These EPR measurements are described below in more detail.

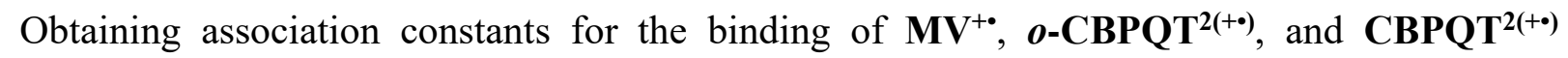
inside of $\mathbf{M S}^{\mathbf{2}(+\bullet)}$ is not an easy task on account of the comparative weaknesses of the complexes themselves and the presence of other inter- and intra-molecular radical-pairing interactions involving these persistent radicals. The association constants were, however, estimated using the molar absorptivity of the NIR band of $[\mathbf{M S} \subset \boldsymbol{m}-\mathbf{C B P Q T}]^{\mathbf{4 ( + )}}$ for the determination of the concentrations of radical-paired species in mixtures of $\mathbf{M S} \mathbf{S}^{\mathbf{2 ( + \bullet})}$ with the other radical cations. This approach assumes that each viologen-viologen radical-pairing interaction contributes the same amount to the molar absorptivity in the NIR region, regardless of the particular identity of the viologen radical cations. This assumption is a necessary one since the molar absorptivities of these weakly bound complexes cannot be directly measured at accessible concentrations. Using this method of approximation, we have shown that $[\text { MSco-CBPQT }]^{4(+\bullet)}$ has a relatively low association constant on the order of $10^{2} \mathrm{M}^{-1}$, followed by $10^{1} \mathrm{M}^{-1}$ for both $[\mathbf{M S} \subset \mathbf{M V}]^{\mathbf{3 ( + \bullet})}$ and $[\mathrm{MS} \subset \mathrm{CBPQT}]^{\mathbf{4}(+\bullet)}$. Thus, it appears that the association constant for the formation of the strongly bound complex $[\mathbf{M S} \subset \boldsymbol{m}-\mathbf{C B P Q T}]^{\mathbf{4 ( + \bullet )}}$ is two to three orders of magnitude larger than that of $[\text { MSco-CBPQT }]^{4(+\bullet)}$, and exceeds that of $[\mathrm{MS} \subset \mathbf{M V}]^{3(+\bullet)}$ and $[\mathrm{MS} \subset \mathrm{CBPQT}]^{4(+\bullet)}$ by at least three orders of magnitude.

The enthalpy $\left(\Delta H_{\mathrm{a}}=-19.3 \pm 1.5 \mathrm{kcal} / \mathrm{mol}\right)$ and entropy $(\Delta S=-41.8 \pm 4.8 \mathrm{cal} / \mathrm{mol} \cdot \mathrm{K})$ of binding were determined for $[\mathbf{M S} \subset \boldsymbol{m}-\mathbf{C B P Q T}]^{\mathbf{4 ( + \bullet )}}$ based on a Van 't Hoff analysis (see Supporting Information) of the variable temperature UV-Vis-NIR spectra (Figure 2a) from four 
1:1 molar ratio samples $(0.050 \mathrm{mM}$ of each cyclophane in $\mathrm{MeCN})$ of $\boldsymbol{m}$-CBPQT $\mathbf{C}^{\mathbf{2}(+\bullet}$ with $\mathbf{M S}^{2(+\bullet)}$. These results reveal that $[\mathbf{M S} \subset \boldsymbol{m}-\mathbf{C B P Q T}]^{4(+\bullet)}$ has an even more favorable heat of formation than that $\left(\Delta H_{\mathrm{a}-\text { Trisradical }}=-15.2 \pm 0.5 \mathrm{kcal} / \mathrm{mol}\right)^{11 \mathrm{~b}}$ observed for $[\mathbf{C B P Q T} \subset \mathbf{M V}]^{\mathbf{3 ( + \bullet})}$, but that the latter occurs with a lower entropic penalty $\left(\Delta S_{\mathrm{a}-\text { Trisradical }}=-29.3 \pm 1.6 \mathrm{cal} / \mathrm{mol} \bullet \mathrm{K}\right)^{11 \mathrm{~b}} \mathrm{such}$ that both complexes have similar binding constants at $25^{\circ} \mathrm{C}$. The high enthalpy of binding for the tetraradical complex suggests that the contribution from additional radical-pairing outweighs the effect of increased charge repulsion in this complex. The increased entropic penalty for the larger complex can be attributed to the additional degrees of freedom that must be suppressed in order to align all of the aromatic units present in both cyclophanes in order to permit effective binding.

Another potentially important influence on the entropy and enthalpy of binding for host-guest pairs is solvation. This factor leads to a more favorable $\Delta S$ of complexation for larger hosts and guests as a result of the greater amount of solvent that is released from the interior and exterior of the host and guest, respectively. Conversely, displacement of solvation from the larger, more highly charged $\boldsymbol{m}$-CBPQT ${ }^{2(+\bullet)}$ guest should be more enthalpically unfavorable than that for the smaller $\mathbf{M V}^{+\bullet}$ guest. Hence, solvation is expected to make contributions to the entropy and enthalpy of complexation that are opposite to the differences in these parameters that are experimentally observed between the trisradical and tetraradical complexes, suggesting that solvation does not make a major contribution to the thermodynamics of this system.

In addition to comparisons with the other radical-based supramolecular complexes, it is worth noting that binding present in $[\mathbf{M S} \subset \boldsymbol{m}-\mathbf{C B P Q T}]^{\mathbf{4 ( + \bullet )}}$ is at least an order of magnitude stronger than has been observed for the tetracationic $\mathbf{M S}^{4+}$ with ferrocenes, ${ }^{18}$ even when the ferrocene 
guests include additional hydrogen-bond recognition arms. The $[\mathbf{M S} \subset \boldsymbol{m}-\mathbf{C B P Q T}]^{\mathbf{4}(+\bullet)}$ complex is also about an order of magnitude stronger than the association of $\mathrm{C}_{60}$ in an even larger congener $^{15 \mathrm{e}}$ of the $\mathbf{C B P Q T}^{4+}$ host design, which requires a well-chosen solvent mixture to facilitate entropy-driven binding.

X-ray Crystallography. A 1:1 molar ratio solution of $\mathbf{M S} \cdot 2 \mathrm{PF}_{6}$ and $\boldsymbol{m}$-CBPQT•2PF 6 in $\mathrm{MeCN}$ was prepared by reduction of a solution of the tetracationic cyclophanes using $\mathrm{Zn}$ dust, as described above for use in the spectroscopic investigations. Vapor diffusion of ${ }^{i} \operatorname{Pr}_{2} \mathrm{O}$ into this solution provided dark purple crystals in two distinct crystal habits. One morphology consisted of long, very thin crystals that were unsuitable for characterization by single crystal X-ray diffraction, while the other crystals were large, block-like ones that diffracted strongly. Note that the trisradical complex $[\mathbf{C B P Q T} \subset \mathbf{M V}] \cdot 3 \mathrm{PF}_{6}$ is also known to crystallize ${ }^{11 \mathrm{c}}$ in multiple distinct morphologies that are similar to those obtained for $[\mathbf{M S} \subset \boldsymbol{m}-\mathbf{C B P Q T}] \bullet 4 P F$. Single-crystal XRD analysis (Figure 3) of one of the large crystals of [MS $\subset$ m-CBPQT]•4PF6 confirmed that they contain $\boldsymbol{m}$-CBPQT ${ }^{2(+\bullet)}$ and $\mathbf{M S}^{\mathbf{2}(+\bullet)}$ bound together in a 1:1 host-guest complex. The solid-state superstructure of this complex is in agreement with the solution-state studies that indicate the formation of a strongly bound 1:1 complex in MeCN. Surprisingly though, two distinct coconformations of $[\mathbf{M S} \subset \mathbf{m}-\mathbf{C B P Q T}]^{\mathbf{4 ( + \bullet )}}$ are present in the superstructure: they differ significantly with respect to the conformation of the smaller cyclophane $\boldsymbol{m}$-CBPQT ${ }^{2(+\bullet)}$. In one of the coconformations of $[\mathbf{M S} \subset \boldsymbol{m}-\mathbf{C B P Q T}]^{\mathbf{4 ( + )}}$, the smaller cyclophane adopts an unusual conformation (Figure 3a-c) in which the two $m$-xylylene linkers and the long axes of both viologen units are nearly perfectly coplanar. This relative orientation of the $m$-xylylene linkers in $\boldsymbol{m}$-CBPQT $\mathbf{T}^{\mathbf{2}(+\bullet)}$ is 
henceforth referred to as the linear conformation of this cyclophane. The other co-conformation features the $\boldsymbol{m}$-CBPQT ${ }^{2(+\bullet)}$ cyclophane in a chair-like conformation (Figure 3d,e). Despite these differences, the viologen units of both cyclophanes are oriented (Figure 3c,e) similarly with respect to each other in each co-conformation of $[\mathbf{M S} \subset \boldsymbol{m} \text {-CBPQT }]^{4(+\cdot)}$. In particular, both coconformations feature near perfect alignments of the centroids of the viologen units, and for each complex, the two planes formed by the four nitrogen atoms of each cyclophane are offset by $10-$ $12^{\circ}$ from a perpendicular alignment with respect to each other. These structural features correspond well to those determined previously for $[\mathbf{C B P Q T} \subset \mathbf{M V}] \cdot 3 \mathrm{PF}_{6}$, and presumably the relative orientations of the viologen units in the two complexes provide maximum overlap of the SOMO's of the hosts and guests. Further quantitative analysis of the superstructure of [MS $\subset \mathbf{m}$ CBPQT $]^{4(+\bullet)}$ is now presented along with comparisons to the structures of the individual cyclophanes $\boldsymbol{m}$-CBPQT ${ }^{2(+\bullet)}$ and $\mathbf{M S}^{2(+\bullet)}$.

Since the solid-state structures of salts containing the $\boldsymbol{m}-\mathbf{C B P Q T}^{2(+\bullet)}$ dication have not been examined previously, we sought to determine the crystallographic structure of $\boldsymbol{m}-\mathrm{CBPQT} \cdot 2 \mathrm{PF} 6$ in order to compare it with the structure of $[\mathrm{MS} \subset \boldsymbol{m}-\mathrm{CBPQT}] \bullet 4 \mathrm{PF}_{6}$. Crystals of $\boldsymbol{m}-\mathrm{CBPQT} \cdot 2 \mathrm{PF}_{6}$ were grown as described above for $[\mathrm{MS} \subset \boldsymbol{m}-\mathbf{C B P Q T}] \bullet 4 \mathrm{PF}_{6}$, and the solid-state structure was determined by single crystal XRD analysis. This structure also features two distinct conformations (Figure 4) of the $\boldsymbol{m}$-CBPQT ${ }^{2(+\cdot)}$ dication, and these conformations are qualitatively similar to those present in the solid state of $[\mathrm{MS} \subset \boldsymbol{m}-\mathbf{C B P Q T}] \bullet 4 \mathrm{PF}$. The two conformations of the cyclophane differ, however, much more significantly in their quantitative aspects compared with those observed in the host-guest superstructure. In particular, the unbound linear structure (Figure 4c) of $\boldsymbol{m}-\mathbf{C B P Q T}^{\mathbf{2}(+)}$ features an unusual distortion in which the two 
viologen units are pinched together in the middle, providing a centroid-to-centroid distance of only $3.6 \AA$. Although this distance is longer than is usually observed $(3.1-3.3 \AA)$ for unrestricted radical-radical interactions involving viologen radical cations, ${ }^{11,27}$ we still associate it with attractive intramolecular radical pairing, considering the significant distortion of the cyclophane that is necessary to achieve this relatively short contact. In contrast, the other conformation of unbound $\boldsymbol{m}$-CBPQT $\mathbf{T}^{2(+)}$ is once again chair-like, with a centroid-to-centroid distance $(5.6 \AA)$ for the viologen units that is $2 \AA$ wider than present in the linear conformation. The considerably wider viologen-viologen spacing in the chair-like conformation precludes the presence of any intramolecular radical-pairing interactions, making this conformation of $\boldsymbol{m}$ -

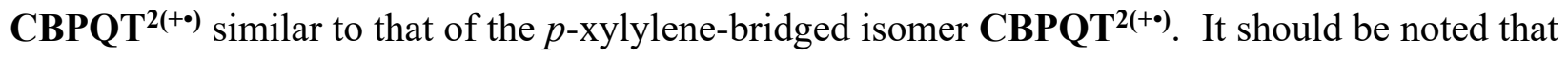
the two conformations are present in a $1: 1$ ratio in the crystal of $\boldsymbol{m}-\mathbf{C B P Q T} \cdot 2 \mathrm{PF}_{6}$, whereas the solution-state UV-Vis-NIR spectrum of $\boldsymbol{m}$-CBPQT ${ }^{2(+\bullet)}$ indicates that only a very small fraction $(\leq 5 \%)$ of the cyclophane is engaged in intramolecular radical pairing. It follows that crystal packing forces may be contributing to the relatively large proportion of the radically-paired, linear conformation of $\boldsymbol{m}-\mathbf{C B P Q T}^{\mathbf{2 ( + \bullet})}$ in the solid state.

The solid-state (super)structures of $\mathbf{M S} \cdot 2 \mathrm{PF}_{6},{ }^{28} \boldsymbol{m}-\mathbf{C B P Q T} \cdot 2 \mathrm{PF}_{6}$, and $[\mathrm{MS} \subset \boldsymbol{m}-\mathbf{C B P Q T}] \bullet 4 \mathrm{PF}_{6}$ are displayed for comparison in Figure 5. The square-shaped cyclophane has longer viologen centroid-to-centroid distances (11.0 $\AA$, Figure 5b; $11.3 \AA$, Figure 5c) in the [MScmCBPQT] ${ }^{4} 4 \mathrm{PF}_{6}$ superstructure than that $(10.6 \AA)$ observed in the structure of $\mathbf{M S} \cdot 2 \mathrm{PF}$. This observation indicates that $\mathbf{M S}^{\mathbf{2 ( + \bullet})}$ must expand somewhat in order to accommodate the large, three-dimensional $\boldsymbol{m}$-CBPQT ${ }^{2(+\bullet)}$ guest. For the guest in $[\mathbf{M S} \subset \boldsymbol{m}-\mathbf{C B P Q T}]^{\mathbf{4}(+\bullet)}$, the viologen centroid-to-centroid distance is shorter for the linear conformation (4.7 $\AA$, Figure $5 \mathrm{~b})$ than for the 
chair-like one $(5.1 \AA)$, consistent with the trend exhibited for these two conformations in $\boldsymbol{m}$ CBPQT·2PF6. The viologen-viologen spacings differ much more significantly in the latter structure, however, than in the host-guest complexes. It appears that complexation leads to a significant expansion in the viologen-viologen distances of the linear conformation from 3.6 to 4.7 $\AA$, while somewhat contracting this distance (5.6 to $5.1 \AA$ ) for the chair-like conformation.

Comparisons of the solid-state superstructures of the radical cyclophanes, and complexes thereof, are informative with respect to how intramolecular and local noncovalent bonding interactions influence the extended packing of the viologen radical cations. The square diradical dication packs (Figure 5a) in columns held together by fully eclipsed viologen units, much like the packing observed in the $\mathrm{PF}_{6}^{-}$salts of $\mathbf{C B P Q T}^{+\bullet}$ and its trisradical complex with $\mathbf{M V}^{+\bullet}$. The chair-like conformation of $\boldsymbol{m}$-CBPQT $\mathbf{T}^{\mathbf{2}(+)}$ also packs (Figure $5 \mathrm{f}, \mathrm{g}$ ) in perfectly eclipsed columns. In contrast, the linear conformation of $\mathbf{m}-\mathbf{C B P Q T}^{\mathbf{2}(+\bullet)}$, which features two close intramolecular viologen contacts, does not exhibit (Figure 5g) extended stacking based on radical-radical interactions. We attribute this difference to intramolecular radical pairing, which reduces the propensity of the radicals to engage in additional intermolecular radical interactions. The hostguest complex $[\mathbf{M S} \subset \boldsymbol{m}-\mathbf{C B P Q T}]^{\mathbf{4 ( + \bullet )}}$ also does not exhibit well-aligned packing into columns. Although there are columns present with alternating stacking of the two co-conformers of the complex, the alignment between them is relatively poor. As a result, there is only limited overlap of the viologen units from one complex to the next, suggesting relatively weak attractive interactions at most. The tetraradical complex $[\mathbf{M S} \subset \boldsymbol{m}-\mathbf{C B P Q T}]^{\mathbf{4 ( + \bullet )}}$ features efficient pairing of both viologen radicals on the smaller cyclophane (see DFT results below) with both radicals on the square cyclophane, thus reducing the energetic benefit of extended viologen interactions. It is 
noteworthy that the packing of these cyclophanes can be influenced by inter- and intramolecular radical-pairing interactions. The ability to modulate the superstructures of viologens and other redox active organic materials could prove useful for tuning the semiconductor properties ${ }^{11 \mathrm{c}}$ of these species in the solid state.

Computational Investigations. It is conceivable that (super)structural features of the host-guest complex and component cyclophanes differ between the solid- and solution-states. This possibility becomes apparent from the inconsistency between the crystal structure of $\boldsymbol{m}$ CBPQT 2 PF $_{6}$ and the UV-Vis-NIR data for this compound in MeCN. It was because of this experimental observation that we sought to obtain insight into the solution-state (super)structures using DFT calculations ${ }^{29}$ employing the M06- $2 \mathrm{X}^{30}$ functional and the $6-311 \mathrm{G}(\mathrm{d}, \mathrm{p})^{31}$ basis set. In order to provide a consistent computational framework for studying the noncovalent bonding interactions in this system we included D3 van der Waals corrections ${ }^{32}$ in the presence of the Poisson-Boltzmann solvation model $^{33}$ for $\mathrm{MeCN}$. The (super)structures, calculated for the individual cyclophanes $\left(\mathbf{M S}^{\mathbf{2 ( + \bullet}} \mathbf{D F T}\right.$ and $\boldsymbol{m}$-CBPQT ${ }^{2(+\bullet)}$ DFT $)$ and host-guest complex $([\mathbf{M S} \subset \boldsymbol{m}$ CBPQT $]^{4(+\bullet)}$ DFT), are presented in Figure 6, and include all (co)conformations that were identified by single crystal XRD analysis. The linear conformation (Figure 6b) of $\boldsymbol{m}$ CBPQT $^{2(+\bullet)}$ DFT was calculated to be $2.33 \mathrm{kcal} / \mathrm{mol}$ more stable than the chair-like conformation (Figure 6c). This energetic preference was preserved qualitatively for the calculated (super)structures of the co-conformations of $[\mathbf{M S} \subset \boldsymbol{m}-\mathbf{C B P Q T}]^{4(+\bullet)}$ DFT. In the case of the hostguest complex, however, the two co-conformations differ in energy by only $0.18 \mathrm{kcal} / \mathrm{mol}$, a negligible difference for such DFT calculations. 
In the case of the individual cyclophanes, there are significant differences between the experimental solid-state structures and the calculated structures. The DFT calculations predict a wider viologen-to-viologen spacing (11.17 $\AA$, Figure 6a) in $\mathbf{M S}^{\mathbf{2 ( + \bullet )}} \mathbf{D F T}$ than was found (10.6 $)$ in the corresponding crystal structure. The linear conformation of $\boldsymbol{m}-\mathbf{C B P Q T}^{\mathbf{2 ( + \bullet}} \mathbf{\text { DFT }}$ also features a viologen-viologen spacing (4.64 $\AA$, Figure $6 b)$ that is considerably wider than that $(3.6 \AA)$ in the corresponding solid-state structure. In this case, the discrepancy is considerably larger than that for the molecular square. The other calculated (super)structures (Figure $6 \mathrm{c}-\mathrm{g}$ ), however, all correspond very closely to those determined experimentally. Additionally, both of the individual diradical cyclophanes were predicted to exist in triplet states, a prediction which is consistent with the UV-Vis-NIR spectra and EPR measurements (see below), both of which indicate that the individual cyclophanes exist in solution without significant intramolecular radical-pairing interactions. Thus, it appears that the DFT calculations are superior, relative to the empirically determined solid-state (super)structures, at providing accurate representations of the solutionstate (super)structures, presumably because of crystal packing forces present in the solid state. The apparent accuracy of the DFT results is notable since these calculations predict that the molecular square is almost the perfect size to bind $\boldsymbol{m}$-CBPQT $\mathbf{T}^{\mathbf{2 ( + \bullet}} \mathbf{D F T}$, requiring expansion or

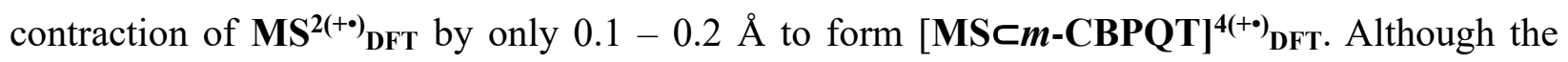
linear conformation of $\boldsymbol{m}$-CBPQT $\mathbf{T}^{\mathbf{2 ( + \bullet}} \mathbf{D F T}$ differs only slightly in $[\mathrm{MS} \subset \boldsymbol{m}-\mathbf{C B P Q T}]^{\mathbf{4 ( + \bullet )}} \mathbf{D F T}$, the chair-like conformation of $\boldsymbol{m}$-CBPQT ${ }^{\mathbf{2}(+\bullet)}$ DFT is contracted by ca. $0.5 \AA$ in the calculated hostguest complex, much as is observed in the solid state.

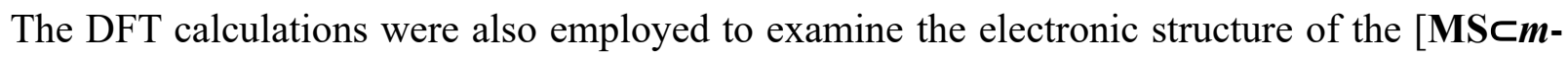
CBPQT $]^{4(+\bullet)}$ host-guest complex. The singlet state of the host-guest complex was predicted to 
have the lowest energy, consistent with the expectation that complexation is driven by strong pairing of the two unpaired radicals on the host with the two radicals on the guest. This intermolecular interaction was probed further through examination of the molecular orbitals (Figure 7) of the host-guest complex. The HOMO and HOMO-1 orbitals indicate, as expected, significant in-phase mixing between the SOMOs of the host and guest viologen units. The HOMO orbital exhibits out-of-phase mixing of the two viologen units across the wide spacing of the guest molecule, while the HOMO-1 is symmetric about the mirror plane that lies between these two viologen units. Since the spacing of the viologen units in $\boldsymbol{m}-\mathbf{C B P Q T}^{\mathbf{2}(+)} \mathbf{D F T}$ is too wide for there to be a significant interaction, the HOMO and HOMO-1 are very close in energy. In contrast, the LUMO exhibits significant out-of-phase mixing of the orbitals on the guest with those on the host, an antibonding interaction that makes this orbital significantly higher in energy (less stable) than those of the HOMO and HOMO-1.

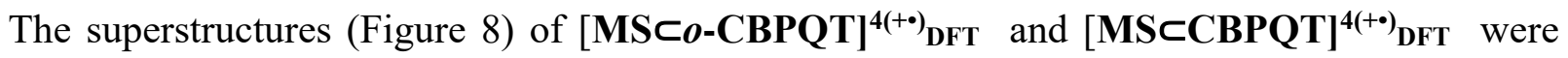
also examined computationally, with the binding energies compared with that determined for $[\mathrm{MS} \subset \boldsymbol{m}-\mathrm{CBPQT}]^{4(+\bullet)}$ DFT. The superstructure of $[\mathrm{MS} \subset \boldsymbol{o}-\mathrm{CBPQT}]^{4(+\bullet)}$ DFT reveals that this very narrow cyclophane makes a close contact with only one of the viologen units on the inside of the molecular square. As a consequence, the formation of this complex provides only one radical pairing interaction, and the electronic ground state is predicted to be a spin triplet. In contrast, the host-guest complex of $\mathbf{M S}^{\mathbf{2 ( + \bullet}}$ DFT with the larger CBPQT $^{\mathbf{2 ( + \bullet})}$ DFT cyclophane has two particularly close $(3.10 \AA)$ viologen-viologen contacts and is predicted to have a spin singlet ground state. In this latter complex, the host $\mathbf{M S}^{\mathbf{2}(+\bullet)}$ DFT expands considerably in order to accommodate the widely spaced guest, a requirement that leads to the prediction of a weak, but favorable energy of 
binding $(\Delta E=-7.65 \mathrm{kcal} / \mathrm{mol})$. The smallest cyclophane $\boldsymbol{o}-\mathbf{C B P Q T}^{\mathbf{2 ( + \bullet )}} \mathbf{D F T}$ is also predicted to bind inside $\mathbf{M S}^{2(+\bullet)}$ DFT with a weakly favorable energy $(\Delta E=-4.06 \mathrm{kcal} / \mathrm{mol})$, while $[\mathbf{M S} \subset \boldsymbol{m}$ CBPQT $]^{4(+\bullet)}$ DFT was found to have a highly favorable energy of binding $(\Delta E=-16.07 \mathrm{kcal} / \mathrm{mol})$. These results follow the trend determined from solution-phase studies, and further support the conclusion that the $m$-xylylene-linked cyclophane is particularly well-proportioned for binding inside of $\mathbf{M S}^{2(+\bullet)}$.

EPR Characterization. The electronic structure of $[\mathrm{MS} \subset \boldsymbol{m}-\mathrm{CBPQT}]^{4(+\bullet)}$ was probed by EPR spectroscopy. A comparison of the relative integrated EPR signal intensities of equimolar MeCN

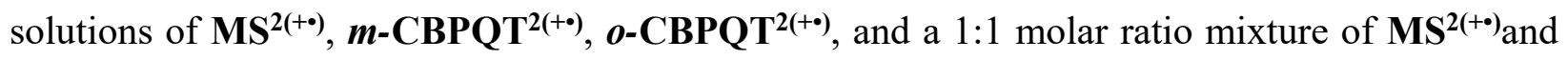

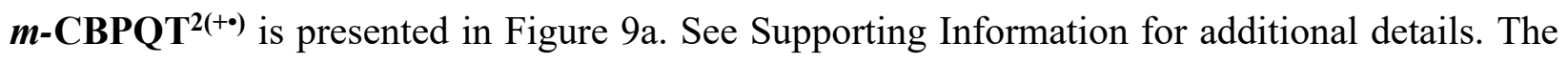
highest intensities are observed for the individual solutions of $\mathbf{M S}^{\mathbf{2 ( + \bullet )}}$ and $\mathbf{m}$-CBPQT $\mathbf{T}^{\mathbf{2}(+\bullet)}$ while

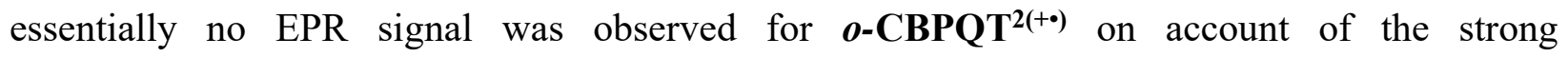
intramolecular radical pairing in this latter compound. The intensity for $\boldsymbol{m}-\mathbf{C B P Q T}^{\mathbf{2}(+\bullet)}$ is slightly lower than that for $\mathbf{M S}^{2(+\bullet)}$, suggesting that a small, but measurable, amount of the $\boldsymbol{m}$ CBPQT $^{2(+\bullet)}$ cyclophane also exists in a radically paired singlet state in solution. The solution containing a mixture of $\mathbf{M S}^{\mathbf{2 ( + \bullet})}$ and $\boldsymbol{m}-\mathbf{C B P Q T ^ { 2 ( + \bullet ) }}$ has a very low intensity that is less than onetenth of that expected from non-interacting diradical compounds, i.e., the sum of the individually measured diradical intensities. Since the host-guest complex is expected to exist as a singlet, the weak EPR signal for the mixed solution can be attributed to a small percentage $(<10 \%)$ of the diradical cyclophanes that are present in the unbound form. The intensity measured at $25{ }^{\circ} \mathrm{C}$ was compared with that of the individual cyclophanes in order to determine the concentrations of 
host, guest, and host-guest complex. From these analyses, we obtained an association constant $\left(K_{a}=(1.7 \pm 0.25) \times 10^{5} \mathrm{M}^{-1}\right.$ from three measurements $)$ which is similar to that $\left(K_{\mathrm{a}}=(1.12 \pm\right.$ 0.08) $\times 10^{5} \mathrm{M}^{-1}$ ) based on the most consistent UV-Vis-NIR measurements.

More thermodynamic information on the tetraradical tetracationic complex [MScmCBPQT] ${ }^{4(+\bullet)}$ was obtained by collecting additional EPR spectra (Figure 9b) at temperatures ranging from -30 to $+70{ }^{\circ} \mathrm{C}$ in $\mathrm{MeCN}$. These spectra reveal a reduction of the radical signal at lower temperatures, consistent with an increase in the ratio of paired to unpaired radical species in solution, until almost no EPR signal is detected at $-30^{\circ} \mathrm{C}$. Conversely, at higher temperatures there is a greater entropic penalty involved in the formation of the complex and the EPR signal increases significantly as a consequence of the dissociation of the complex. The association constants were calculated at each temperature, and a temperature-dependent Van ' $t$ Hoff analysis provided the thermodynamic parameters $\Delta H_{298 K}=-17.9 \mathrm{kcal} / \mathrm{mol}$ and $\Delta S_{298 K}=-34.2 \mathrm{cal} / \mathrm{mol} \cdot \mathrm{K}$. See Supporting Information for more details. The magnitudes of both the enthalpy and entropy of binding are smaller than those determined from variable temperature UV-Vis-NIR measurements. Despite these differences between the methods of measurement, the EPR studies support the trend that, relative to the trisradical trication $[\mathbf{C B P Q T} \subset \mathbf{M V}]^{\mathbf{3 ( + \bullet})}$, the tetraradical complex forms with more negative enthalpy and entropy changes.

Electrochemistry. Radical-pairing interactions lend stability to the radical-cation oxidation states of viologen units, a phenomenon which can be probed using cyclic voltammetry (CV). It should be noted at the outset that the highest quality electrochemical data was obtained at relatively low concentrations $(0.05-0.2 \mathrm{mM})$ of $\mathbf{M S} 4 \mathrm{PF}_{6}$ and $\boldsymbol{m}$-CBPQT•4PF 6 . At higher 
concentrations $(\geq 0.5 \mathrm{mM})$, it became evident that the more positive redox couple observed for mixtures of $\mathbf{M S} \bullet 4 \mathrm{PF}_{6}$ and $\boldsymbol{m}$-CBPQT•4PF 6 displays inconsistent behavior at higher scan rates. Additionally, the more negative redox couple that was observed for isolated solutions of MS•4PF 6 is not consistently reversible for concentrations $\geq 0.5 \mathrm{mM}$. Visual inspection of the working electrode revealed that, although a noticeable amount of material is deposited on the electrode surface during higher concentration measurements, these problems are not observed when data is collected at lower concentrations $(\leq 0.2 \mathrm{mM}$ of each cyclophane $)$ of the analytes. Furthermore, by using lower concentrations of each analyte, ferrocene can be used as an internal redox standard without interference from the formation ${ }^{18}$ of a host-guest complex between $\mathbf{M S}^{\mathbf{4}}$ and ferrocene.

The CVs of $\mathbf{M S} \bullet 4 \mathrm{PF}_{6}, \boldsymbol{m}-\mathbf{C B P Q T} \bullet 4 \mathrm{PF}_{6}$, and of an equimolar mixture of the two in $\mathrm{MeCN}$ (0.1 $\mathrm{M} \mathrm{TBAPF}_{6}$ electrolyte) are compared in Figure 10 with a scan rate of $0.2 \mathrm{~V} / \mathrm{s}$. The CVs of the individual cyclophanes are consistent with previous electrochemical studies ${ }^{20 b, 25}$ carried out on these compounds. They display redox characteristics typical of viologen derivatives. The molecular square exhibits two reversible redox waves, while for $\boldsymbol{m}$-CBPQT•4PF 6 , the more negative wave is split into two distinct, but closely separated, redox events. Notably, the five distinct reduction waves of the cyclophanes (two for $\mathbf{M S} \bullet 4 \mathrm{PF}_{6}$ and three for $\boldsymbol{m}-\mathbf{C B P Q T} \bullet \mathbf{P F} 6$ ) are not individually observed in the voltammogram recorded on a solution containing a mixture of each cyclophane in a 1:1 ratio. Instead, this CV displays only two single, sharp reduction waves, indicating the formation of the tetraradical host-guest complex.

Additional information about the formation of the host-guest complex is evident from quantitative comparisons of the CVs of the individual cyclophanes with that of the mixed 
solution. The first reduction of the equimolar solution occurs at a more positive potential $\left(E_{\text {red }}=\right.$ $-0.705 \mathrm{~V})$ than those observed for either of the individual compounds $\left(E_{\mathrm{red}}=-0.730 \mathrm{~V}\right.$ for $\boldsymbol{m}$ $\mathrm{CBPQT} \cdot 4 \mathrm{PF}_{6}$ and $-0.744 \mathrm{~V}$ for $\mathrm{MS} \bullet 4 \mathrm{PF}_{6}$ at $0.2 \mathrm{~V} / \mathrm{s}$ ), indicating the stabilization of the radical state that is provided upon formation of the host-guest complex. The second reduction of the mixed sample appears at a more positive potential $\left(E_{\text {red }}=-1.209 \mathrm{~V}\right)$ than that $\left(E_{\text {red }}=-1.232 \mathrm{~V}\right)$ for the most negative reduction wave of $\boldsymbol{m}-\mathbf{C B P Q T} \bullet 4 \mathrm{PF}_{6}$, yet is more negative than the average of all of the corresponding reductions for both individual cyclophanes $\left(E_{\text {red-average }} \approx-1.18 \mathrm{~V}\right)$. Thus, the mixed solutions exhibits a net stabilization of the radical oxidation state of the cyclophanes with respect to oxidation and reduction, which can be attributed to the formation of the tetraradical host-guest complex, as was observed ${ }^{11 a}$ for the previously studied trisradical assembly.

The more negative redox couple of the equimolar solution is reversible, suggesting that the $[\mathrm{MS} \subset \boldsymbol{m}-\mathrm{CBPQT}]^{4(+\bullet)} /[\mathrm{MS} \subset \boldsymbol{m}-\mathrm{CBPQT}]^{0}$ redox couple is not influenced by dynamic processes at scan rates of $0.2 \mathrm{~V} / \mathrm{s}$. This observation indicates that $[\mathbf{M S} \subset \boldsymbol{m}-\mathbf{C B P Q T}]^{0}$ does not dissociate during the timeframe of the measurement, although it is also possible that fast association/dissociation of the cyclophanes occurs since rapid dynamic processes are also consistent with electrochemical reversibility. Comparison of the $E_{1 / 2}$ value for this redox couple with those of the individual cyclophanes indicates a similar level of stabilization $(30 \mathrm{mV})$ to that indicated by a comparison of the reduction peaks. In contrast, the more positive redox couple of the mixed solutions exhibits distinct behavior in which the oxidation wave is split into two closely overlapping peaks with the more well-defined peak $(-0.551 \mathrm{~V})$ shifted by ca. $150 \mathrm{mV}$ 
more positive than the corresponding reduction $(-0.705 \mathrm{~V})$. Note, for comparison, that the reversible $\mathrm{Fc} / \mathrm{Fc}^{+}$couple exhibits a much smaller $\Delta E_{\mathrm{p}}$ of $65 \mathrm{mV}$ under these conditions.

The behavior of the more positive redox couple was probed by recording CVs (Figure 11) of the equimolar solutions of $\mathbf{M S} \bullet 4 \mathrm{PF}_{6}$ and $\boldsymbol{m}$-CBPQT•4PF $6(0.05 \mathrm{mM}$ each) at different scan rates. At a low scan rate of $0.025 \mathrm{~V} / \mathrm{s}$, this redox couple exhibits reversible behavior, with only a single oxidation wave being observed. Increasing the scan rate to $0.1 \mathrm{~V} / \mathrm{s}$ or $0.2 \mathrm{~V} / \mathrm{s}$ (Figure $11 \mathrm{~b}, \mathrm{c})$ does not significantly alter the reduction wave, while the oxidation wave is broadened and shifted significantly to more positive potentials. The broadening appears to be a consequence, in part at least, to the separation of the oxidation wave into two distinct oxidation events, which is more clearly evident from higher scan rate CVs $(1-50 \mathrm{~V} / \mathrm{s}$, Figure $11 \mathrm{e}-\mathrm{f})$. The more positive oxidation wave continues to shift significantly in a positive direction as the scan rate is increased, while the potentials for the reduction wave and the less positive oxidation wave exhibit only small to moderate dependences on the scan rate. The less positive oxidation wave does, however,

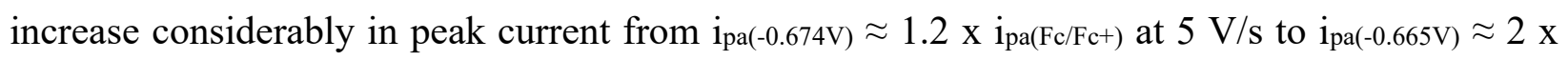
$\mathrm{i}_{\mathrm{pa}\left(\mathrm{Fc}_{\mathrm{Fc}}+\mathrm{F}\right.}$ at $50 \mathrm{~V} / \mathrm{s}$, and this was accompanied by a corresponding decrease in the more positive

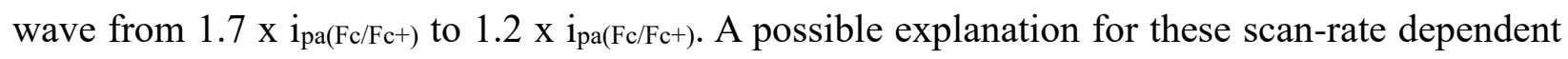
characteristics is that, at faster scan rates, the two diradical cyclophanes do not have sufficient time to equilibrate with $[\mathbf{M S} \subset \boldsymbol{m}-\mathbf{C B P Q T}]^{4(+\bullet)}$. As a consequence, two different oxidation peaks are observed, the more negative one corresponding to the oxidation of the unbound cyclophanes $\mathbf{M S}^{2(+\bullet)}$ and $\boldsymbol{m}$-CBPQT ${ }^{2(+\bullet)}$, while the more positive oxidation wave can be attributed to the complex $[\mathbf{M S} \subset \boldsymbol{m}-\mathbf{C B P Q T}]^{\mathbf{4 ( + )}}$ in which the radicals are stabilized toward oxidation. 
The explanation for the scan-rate dependent behavior is supported by additional experiments. The potential window has been increased (Figure 12) to include the more negative redox couple associated with the viologen units, i.e., the radical/neutral redox couple, which had a negligible effect on the potentials observed for the more positive redox couple exhibited by the viologen units. Increasing the potential window (Figure 12a) does, however, decrease the ratio of the peak current of the oxidation wave at $-0.685 \mathrm{~V}$ relative to that of the wave at $-0.50 \mathrm{~V}\left(\mathrm{i}_{\mathrm{pa}}(-0.68 \mathrm{~V}) / \mathrm{i}_{\mathrm{pa}}-\right.$ $0.5 \mathrm{~V})=0.3)$ in comparison to the ratio $\left(\mathrm{i}_{\mathrm{pa}(-0.67) / \mathrm{i}_{\mathrm{pa}}(-0.5 \mathrm{~V})}=0.7\right)$ observed for these two peaks when using a smaller scan window (Figure 11e) at $5 \mathrm{~V} / \mathrm{s}$. This trend is also evident in the CVs recorded at $50 \mathrm{~V} / \mathrm{s}$, in which the ratio $\mathrm{i}_{\mathrm{pa}(-0.67)} / \mathrm{i}_{\mathrm{pa}(-0.46 \mathrm{~V})}=0.9$ is smaller when a wider scan window (Figure $12 \mathrm{~b})$ is used than is observed $\left(\mathrm{i}_{\mathrm{pa}(-0.67)} / \mathrm{i}_{\mathrm{pa}(-0.46 \mathrm{~V})}=1.7\right)$ when a smaller window (Figure 11f $)$ is employed. The wider potential range increases the amount of time available at a given scan rate for the $\mathbf{M S}^{\mathbf{2 ( + \bullet )}}$ and $\boldsymbol{m}-\mathbf{C B P Q T}^{\mathbf{2 ( + \bullet )}}$ diradical dications to associate prior to reoxidation, which in turn, increases the concentration of the $[\mathbf{M S} \subset \boldsymbol{m}-\mathbf{C B P Q T}]^{\mathbf{4 ( + \bullet )}}$ tetraradical tetracation while decreasing the concentration of the individual cyclophanes. Consistent with this interpretation of the data, the $\mathrm{CV}$ recorded at $50 \mathrm{~V} / \mathrm{s}$ displays (Figure 12b) a shoulder on the more negative reduction wave, as expected, since the reduction waves for the unbound $\mathbf{M S}^{\mathbf{2 ( + \bullet})}$ and $\boldsymbol{m}$ CBPQT $^{2(+\bullet)}$ components should extend to more positive potentials than the reduction wave for the $[\mathrm{MS} \subset \boldsymbol{m}-\mathrm{CBPQT}]^{4(+\bullet)}$ complex.

The kinetics and thermodynamics associated with the formation of $[\mathbf{M S} \subset \boldsymbol{m}-\mathbf{C B P Q T}]^{\mathbf{4}(+\bullet)}$ should be concentration dependent since host-guest formation is a bimolecular process. Reproducible CVs could not be obtained at high concentrations ( $\geq 0.5 \mathrm{mM}$ of each cyclophane), but good CV data (Figure 13) could be obtained after a more moderate increase from 0.05 to 0.2 
$\mathrm{mM}$ concentrations for both of the cyclophanes. The CVs obtained at $0.2 \mathrm{~V} / \mathrm{s}$ were very similar at both sample concentrations (Figure 10c and 13a), but significant concentration dependent differences were evident at higher scan rates. At $5 \mathrm{~V} / \mathrm{s}$, the $\mathrm{CV}$ (Figure 13b) of the more

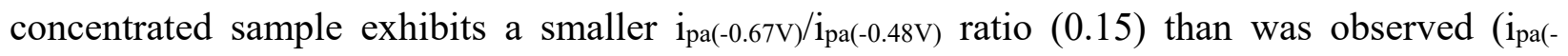
$0.68 \mathrm{~V}) / \mathrm{i}_{\mathrm{pa}(-0.5 \mathrm{~V})}=0.3$, Figure $\left.12 \mathrm{a}\right)$ for the less concentrated sample. At $50 \mathrm{~V} / \mathrm{s}$, this ratio was increased to 0.6 for the more concentrated sample (Figure $13 \mathrm{c}$ ), but was still smaller than that

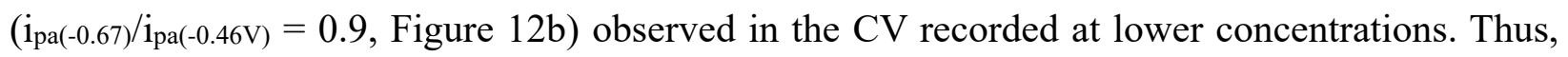
higher concentrations appear to favor the more positive reoxidation wave, an observation which is consistent with the hypothesis that this wave corresponds to the oxidation of the tetraradical tetracationic complex $[\mathbf{M S} \subset \boldsymbol{m}-\mathbf{C B P Q T}]^{\mathbf{4}(+\bullet)}$ which should be favored, bother kinetically and thermodynamically, at higher initial concentrations of the cyclophanes.

These electrochemical investigations reveal some differences in the behavior of the tetraradical

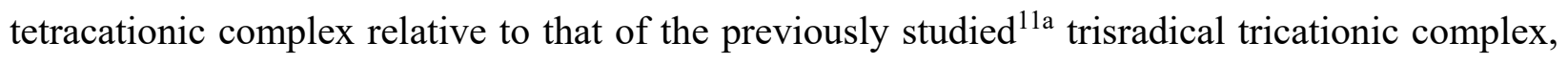
which exhibits an additional redox wave on account of the presence of one unpaired electron. More significantly, however, the trisradical tricationic complex displays an increase in the most positively shifted oxidation wave as the scan rate is increased up to $30 \mathrm{~V} / \mathrm{s}$. This observation contrasts with the behavior of the tetraradical tetracationic complex, in which the most positively shifted wave decreases at high scan rates. These differences can be attributed to slower kinetics

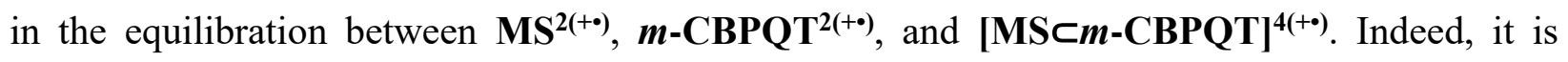
possible to observe the direct oxidation of $[\mathbf{M S} \subset \boldsymbol{m}-\mathbf{C B P Q T}]^{4(+\bullet)}$ at low scan rates because this complex dissociates relatively slowly, whereas at fast scan rates the cyclophanes do not have sufficient time to associate. By contrast, the trisradical tricationic complex appears to associate 
readily even at high scan rates, which are required in order to observe the direct oxidation of the $[\mathbf{C B P Q T} \subset \mathbf{M V}]^{\mathbf{2}(+\bullet)}$ intermediate. Cyclic voltammetry is, however, a relatively challenging technique to use for anything more than semi-quantitative kinetics comparisons, and more detailed investigations of these kinetic differences are beyond the scope of the current investigations.

\section{- CONCLUSIONS}

The dicationic diradical cyclophane $\boldsymbol{m}$-CBPQT $\mathbf{T}^{\mathbf{2}(+)}$ has been shown to bind strongly as a guest inside the cavity of the square-shaped diradical $\mathbf{M S}^{\mathbf{2 ( + \bullet}}$ to form $[\mathbf{M S} \subset \boldsymbol{m}-\mathbf{C B P Q T}]^{4(+\bullet)}$, while smaller and larger potential guests bind much more weakly. A variety of solution-state methods, including UV-Vis-NIR spectroscopy, EPR spectroscopy, and cyclic voltammetry, were used to study the formation and properties of the tetraradical complex. Structural characterization was provided by single crystal X-ray diffraction methods and DFT calculations at the M06-2X-D3 level. Notably, this well characterized complex is only the second example of a host-guest recognition motif based on radical-pairing interactions, following the discovery ${ }^{11 \mathrm{a}}$ of the smaller trisradical complex $[\mathbf{C B P Q T} \subset \mathbf{M V}]^{3(+\bullet)}$ several years ago. Formation of the tetraradical complex is driven by radical-pairing interactions between the two recognition sites present in the host i.e., the two radical viologen units - with two corresponding recognition sites in the guest. These recognition sites are inherently multivalent since they involve two discrete viologenviologen interactions with little electronic communication occurring through the middle of the $\boldsymbol{m}$-CBPQT $\mathbf{T}^{\mathbf{2 ( + \bullet )}}$ guest. A number of other multivalent radical recognition motifs ${ }^{35}$ have previously been reported, but these past examples are all homo-association processes involving compounds with multiple viologen ${ }^{35 a-c}$ or tetrathiafulvalene radical units, ${ }^{35 \mathrm{~d}, \mathrm{e}}$ rather than the selective 
assembly of two distinct components to afford a host-guest complex. Furthermore, to our knowledge, the selectivity of these assemblies has never been demonstrated, while at least some examples are known $^{24 b}$ to be disrupted upon the addition of $\mathbf{C B P Q T}^{\mathbf{2}(+\bullet)}$ to form polypseudorotaxanes based on the trisradical recognition motif.

The evenly numbered, discrete radical-pairing interactions in $[\mathbf{M S} \subset \boldsymbol{m}-\mathbf{C B P Q T}]^{\mathbf{4}(+\bullet)}$ imbue this tetraradical complex with different electronic properties from those exhibited by the odd-electron complex $[\mathrm{CBPQT} \subset \mathrm{MV}]^{3(+\bullet)}$. In particular, $[\mathrm{MS} \subset \boldsymbol{m}-\mathrm{CBPQT}]^{4(+\bullet)}$ is a diamagnetic complex as predicted computationally and determined experimentally by EPR spectroscopy, whereas the trisradical complex exists in a doublet ground state. Additionally, the tetraradical complex displays only two redox couples when examined by cyclic voltammetry, whereas the smaller complex exhibits three reduction events and as many as four oxidation events. There are, however, similarities between the two radical host-guest complexes, e.g., similar electronic stabilization of the radical states of the viologens, and similar relative orientations of the viologen units in the host and the guest. Additionally, the association constants for the two complexes differ by only a small amount (significantly less than one order of magnitude) despite the fact that the new tetraradical complex brings together a larger amount of positive charge. This observation can be attributed to the increased stabilization provided by the multivalent radical recognition in $[\mathrm{MS} \subset \boldsymbol{m}-\mathbf{C B P Q T}]^{4(+\bullet)}$, which compensates for the increased charge repulsion.

The most notable feature of the new $[\mathbf{M S} \subset \boldsymbol{m} \text {-CBPQT] }]^{4(+\bullet)}$ host-guest complex, however, is its increased size relative to that of $[\mathbf{C B P Q T} \subset \mathbf{M V}]^{\mathbf{3 ( + \bullet )}}$. The $\boldsymbol{m}-\mathbf{C B P Q T}^{\mathbf{2 ( + \bullet )}}$ guest in the tetraradical complex is approximately three times the size, with respect to molecular weight, width, and volume, as the $\mathbf{M V}^{(+\bullet)}$ guest, and furthermore, $\boldsymbol{m}$-CBPQT $\mathbf{T}^{\mathbf{2 ( + )}}$ is nearly as large as the 
CBPQT $^{2(+\bullet)}$ host in the tricationic trisradical complex. The considerably expanded size of the host and guest in $[\mathrm{MS} \subset \boldsymbol{m} \text {-CBPQT }]^{\mathbf{4 ( + \bullet}}$ marks the first example of a size-homologue of the viologen cyclophane radical recognition motif, much as differently sized derivatives have been studied for many other classic hosts-guest complexes. As in the case of these seminal examples, there is considerable size-based specificity in the $[\mathrm{MS} \subset \boldsymbol{m}-\mathbf{C B P Q T}]^{4(+\bullet)}$ and $[\mathrm{CBPQT} \subset \mathrm{MV}]^{3(+\bullet)}$ recognition motifs to the extent that that neither component of the tetraradical complex interacts strongly with either component of the trisradical complex. The high selectivity for these hostguest interactions is remarkable considering that both complexes are held together by essentially the same type of radical-pairing-based recognition motif. The orthogonality of the trisradical and tetraradical motifs could be exploited in the assembly of more sophisticated hierarchical structures and mechanically interlocked molecules. We are currently investigating these possibilities using functionalized derivatives of the $\boldsymbol{m}$-CBPQT ${ }^{2(+\bullet)}$ guest.

\section{- ASSOCIATED CONTENT}

\section{Supporting Information}

Experimental details, including crystal structure refinement details, structure cif files, cyclic voltammograms, UV-Vis-NIR spectra, EPR spectra, DFT calculations, and details of data processing. This material is available free of charge via the Internet at http://pubs.acs.org.

\section{- AUTHOR INFORMATION}

Corresponding Author

*stoddart@northwestern.edu

\section{Author Contributions}




\section{Notes}

The authors declare no competing financial interest.

\section{- ACKNOWLEDGEMENTS}

This research is part of the Joint Center of Excellence in Integrated Nano-Systems (JCIN) at King Abdulaziz City of Science and Technology (KACST) and Northwestern University (NU). The authors would like to thank both KACST and NU for their continued support of this research. Computational investigations were supported by the U.S. National Science Foundation under grant no. EFRI-1332411 (W.A. Goddard III and T. Cheng). Electron paramagnetic resonance studies were supported by the U.S. National Science Foundation under grant no. CHE1565925 (M.R. Wasielewski). Y. Wu thanks the Fulbright Scholar Program for a Fellowship and the NU International Institute of Nanotechnology for a Ryan Fellowship. Computational invistigations

\section{- REFERENCES}

(1) (a) Pedersen, C. J. L.Am. Chem.Soc. 1967, 89, 2495 - 2496. (b) Pedersen, C. J. J. Am. Chem.Soc. 1967, 89, 7017 - 7036. (c) Dietrich, B.; Lehn, J.-M., Sauvage, J.-P. Tetrahedron Lett. 1969, 2889 - 2892. (d) Pedersen, C. J. L.Am.Chem.Soc. 1970, 92, 386 - 391. (e) Kyba, E. P.; Helgeson, R. C.; Madan, K.; Gokel, G. W.; Tarnowksi, T. L.; Moore, S. S.; Cram, D. J. L.Am.Chem.Soc. 1977, 99, $2564-2571$.

(2) (a) Lehn, J.-M. Science 1985, 227, 849 - 856. (b) Cram, D. J. Angew. Chem. Int. Ed. 1988, 27, 1009 - 1112. (c) Diederich, F. N. Angew. Chem._Int. Ed. 1988, 27, 362 - 386. (d) Stoddart, J. F. Nature, 1988, 334, 10 - 11. (e) Gutsche, C. D., Calixarenes, Royal Society of Chemistry, Cambridge, 1989. (f) Lehn, J.-M. Angew.Chem.Int.Ed. 1990, 29, 1304 - 1319. (g) Schneider, H.-J. Angew. Chem.Int._Ed. 1991, 30, 1417 - 1436. (h) Diederich, F. N. Cyclophanes, Royal Society of Chemistry, Cambridge, 1991. (i) Gokel, G. W. Crown Ethers and Cryptands, Royal Society of Chemistry, Cambridge, 1991. (j) Dietrich, B.; Viout, P.; Lehn, J.-M. Macrocyclic Chemistry, VCH, New York, 1993. (k) Cram, D. J. Container Molecules and their Guests, Royal Society of Chemistry, Cambridge, 1994. (1) Fyfe, M. C. T.; Stoddart, J. F. Acc.Chem.Res. 1996, 30, 393 - 401. (m) Philp, D.; Stoddart, J. F. Angew. 
Chem. Int. Ed. 1996, 35, 1154 - 1196. (n) Biedermann, F.; Schneider, H.-J. Chem. Rev. 2016, $116,5216-5300$

(3) (a) Piguet, C.; Bünzli, J.-C. G. Chem.Soc._Rev. 1999, 28, 347 - 358. (b) Faul, C. F. J.; Antonietti, M. Adv.Mater. 2003, 15, 673 - 683. (c) Hossain, M. A. Curr. Org. Chem. 2008, 12, 1231 - 1256. (d) Rambo, B. M.; Gong, H.-Y.; Oh, M.; Sessler, J. L. Acc. Chem.Res. 2012, 45, 1390 - 1401. (e) Watt, M. M.; Collins, M. S.; Johnson, D. W. Acc. Chem.Res. 2013, 46, 955 - 966. (f) Dougherty, D. A. Acc.Chem.Res. 2013, 46, 885 - 893. (g) Chifotides, H. T.; Dunbar, K. R. Acc.Chem.Res. 2013, 46, 894 - 906. (h) Beale, T. M.; Chudzinski, M. G.; Sarwar, M. G.; Taylor, M.S. Chem.Soc.Rev. 2013, 42, 1667 - 1680. (i) Kim, S. K.; Sessler, J. L. Acc.Chem.Res. 2014, 47, 2525 - 2536.

(4) (a) Reynolds, J. A.; Gilbert, D. B.; Tanford, C. Proc Natl.Acad.Sci.U.S.A. 1974, 71, 2925 - 2927. (b) Kim, K.; Chem.Soc.Rev. 2002, 31, 96 - 107. (c) Rajamani, S.; Truskett, T. M.; Garde, S. Proc.Natl.Acad.Sci. USA 2005, 102, 9475 - 9480. (d) Chandler, D. Nature 2005, 437, 640 - 647. (e) Palmer, L. C.; Stupp, S. I. Acc.Chem.Res. 2008, 41, 1674 - 1684. (f) Harada, A.; Takashima, Y.; Yamaguchi, H. Chem.Soc.Rev. 2009, 38, 875 - 881. (g) Davis, J. G.; Rankin, B. M.; Gierszal, K. P.; Ben-Amotz, D. Nat.Chem. 2013, 5, 796 - 802.

(5) (a) Hunter, C. A.; Lawson, K. R.; Perkins, J.; Urch, C. J. Chem. Soc., Perkin Trans. 2, 2001, 651 - 669. (b) Meyer, E. A.; Costellano, R. K.; Diederich, F. Angew. Chem.Int.Ed. 2003, 42, 1210 - 1250. (c) Chen, Z.; Lohr, A.; Saha-Möller, C. R.; Würthner, F. Chem.Soc.Rev. 2009, 38, 564 - 584. (d) Salonen, L. M.; Ellermann, M.; Diederich, F. Angew. Chem.Int.Ed. 2011, 50, 4808 - 4842. (e) Martinez, C. R.; Iverson, B. L. Chem. Sci. 2012, 3, 2191 - 2201. (f) Schneider, H.-J. Acc.Chem.Res. 2013, 46, 1010 - 1019. (g) Riley, K. E.; Hobza, P. Acc. Chem.Res. 2013, 46, 927 - 936.

(6) (a) Prins, L. J.; Reinhoudt, D. N.; Timmerman, P. Angew. Chem. Int. Ed. 2001, 40, 2381 2426. (b) Sherrington, D. C.; Taskinen, K. A. Chem. Soc. Rev. 2001, 30 , 83 - 93. (c) Jeffrey, G. A. An Introduction to Hydrogen Bonding; Oxford University Press: New York, 1997. (d) Desiraju, G. R. Acc.Chem.Res. 2002, 35, 565 - 573.

(7) (a) Christensen, J. J.; Eatough, D. J.; Izatt, R. M. Chem. Rev. 1972, 74, 351 - 384. (b) Izatt, R. M.; Bradshaw, J. S.; Nielsen, S. A.; Lamb, J. D.; Christensen, J. J. Chem. Rev. 1985, 85, $271-339$.

(8) Mecozzi, S.; Rebek, J. Chem.Eur.J. 1998, 4, 1016 - 1022.

(9) (a) Hobza, P.; Selzle, H. L.; Schlag, E. W. J. Am. Chem. Soc. 1994, 116, 3500 - 3506. (b) Rajesh, C.; Majumder, C.; Mizuseki, H.; Kawazoe, Y. J. Chem. Phvs. 2009, 130, 124911. (c) 
Andresen, T. L.; Krebs, F. C.; Thorup, N.; Bechgaard, K.; Chem. Mater. 2000, 12, 2428 2433.

(10) (a) Odell, B.; Reddington, M. V.; Slawin, A. M. Z.; Spencer, N.; Stoddart, J. F.; Williams, D. J. Angew. Chem. Int. Ed. 1988, 1547 - 1550. (b) Ashton, P. R.; Odell, B.; Reddington, M. V.; Slawin, A. M. Z.; Spencer, N.; Stoddart, J. F.; Williams, D. J. Angew. Chem. Int. Ed. 1988, 1550 - 1553. (c) Philp, D.; Slawin, A. M. Z.; Spencer, N.; Stoddart, J. F.; Williams, D. J. J. Chem. Soc., Chem. Commun. 1991, 1584 - 1586. (d) Choi, J. W.; Flood, A. H.; Steuerman, D. W.; Nygaard, S.; Braunschweig, A. B.; Moonen, N. N. P.; Laursen, B. W.; Luo, Y.; DeIonno, E.; Peters, A. J.; Jeppesen, J. O.; Xu, K.; Stoddart, J. F.; Heath, J. R. Chem.Eur.J. 2006, 12, $261-279$.

(11) (a) Trabolsi, A.; Khashab, N.; Fahrenbach, A. C.; Friedman, D. C.; Colvin, M. T.; Coti, K. K.; Benítez, D.; Tkatchouk, E.; Olsen, J.-C.; Belowich, M. E.; Carmielli, R.; Khatib, H. A.; Goddard, W. A. III; Wasielewski, M. R.; Stoddart, J. F. Nat. Chem. 2010, 2, 42 - 49. (b) Fahrenbach, A. C.; Barnes, J. C.; Lanfranchi, D. A.; Li, H.; Coskun, A.; Gassensmith, J. J.; Liu, Z.; Benítez, D.; Trabolsi, A.; Goddard, W. A. III; Elhabiri, M.; Stoddart, J. F. L.Am. Chem.Soc. 2012, 134, 3061 - 3072. (c) Fahrenbach, A. C.; Sampath, S.; Late, D. J.; Barnes, J. C.; Kleinman, S. L.; Valley, N.; Hartlieb, K. J.; Liu, Z.; Dravid, V. P.; Schatz, G. C.; Van Duyne, R. P.; Stoddart, J. F. Nano Lett. 2012, 6, 9964 - 9971.

(a) Share, A. I.; Flood, A. H. Nat. Chem. 2010, 2, 349 - 350. (b) Rambo, B. M.; Gong, H.-Y.; Oh, M.; Sessler, J. L. Acc.Chem.Res. 2012, 45, 1390 - 1401. (c) Dale, E. J.; Vermeulen, N. A.; Juríček, M.; Barnes, J. C.; Young, R. M.; Wasielewski, M. R.; Stoddart, J. F. Acc. Chem. Res. 2016, 49, $262-273$.

(13) (a) Ashton, P. R.; Goodnow, T. T.; Kaifer, A. E.; Reddington, M. V.; Slawin, A. M. Z.; Spencer, N.; Stoddart, J. F.; Vicent, C.; Williams, D. J.Angew. Chem.Jnt.Ed. 1989, 28, 1396 - 1399. (b) Anelli, P.-L.; Spencer, N.; Stoddart, J. F. J.Am. Chem. Soc. 1991, 113, 5131 5133. (c) Stoddart, J. F. Chem.Soc.Rev.2009, 38, $1802-1820$.

(14) (a) Collier, C. P.; Mattersteig, G.; Wong, E. W.; Luo, Y.; Beverly, K.; Sampaio, J.; Raymo, F. M.; Stoddart, J. F.; Heath, J. R. Science 2000, 289, 1172 - 1175. (b) Liu, Y.; Flood, A. H.; Bonvallet, P. A.; Vignon, S. A.; Northrop, B. H.; Tseng, H.-R.; Jeppesen, J. O.; Huang, T. J.; Brough, B.; Baller, M.; Magonov, S.; Solares, S. D.; Goddard, W. A. III; Ho, C.-M.; Stoddart, J. F. L.Am.Chem.Soc. 2005, 127, 9745 - 9759. (c) Nguyen, T. D.; Tseng, H.-R.; Celestre, P. C.; Flood, A. H.; Stoddart, J. F. Proc. Natl. Acad. Sci. USA 2005, 102, 
10029 - 10034. (d) Cheng, C.; McGonigal, P. R.; Schneebeli, S. T.; Li, H.; Vermeulen, N. A.; Ke, C.; Stoddart, J. F. Nat. Nanotechnol. 2015, 10, 547 - 553.

(a) Gong, H.-Y.; Rambo, B. M.; Karnas, E.; Lynch, V. M.; Sessler, J. L. Nat. Chem. 2010, 2, 406 - 409. (b) Gong, H.-Y.; Rambo, B. M.; Lynch, V. M.; Keller, K. M.; Sessler, J. L. L.Am.Chem.Soc. 2013, 135, 6330 - 6337. (c) Barnes, J. C.; Juríček, M.; Strutt, N. L.; Frasconi, M.; Sampath, S.; Giesner, M. A.; McGrier, P. L.; Bruns, C. J.; Stern, C. L.; Sarjeant, A. A.; Stoddart, J. F. J.Am.Chem.Soc. 2013, 135, 183 - 192. (d) Juríček, M.; Barnes, J. C.; Dale, E. J.; Liu, W.-G.; Strutt, N. L.; Bruns, C. J.; Vermeulen, N. A.; Ghooray, K.; Sarjeant, A. A.; Stern, C. L.; Botros, Y. Y.; Goddard, W. A. III,; Stoddart, J. F. L.Am. Chem.Soc. 2013, 135, 12736 - 12746. (e) Barnes, J. C.; Dale, E. J.; Prokofjevs, A.; Narayanan, A.; Gibbs-Hall, I. C.; Juríček, M.; Stern, C. L.; Sarjeant, A. A.; Botros, Y. Y.; Stupp, S. I.; Stoddart, J. F. L.Am. Chem.Soc. 2015, 137, 2392 - 2399.

(a) Freeman, W. A.; Mock, W. L.; Shih, N. Y. L.Am.Chem.Soc. 1981, 103, 7367 7368. (b) Kim, J.; Jung, I.-S.; Kim, S.-Y.; Lee, E.; Kang, J.-K.; Sakamoto, S.; Yamaguchi, K.; Kim, K. L.Am.Chem.Soc. 2000, 122, 540 - 541. (c) Day, A. I.; Blanch, R. J.; Arnold, A. P.; Lorenzo, S.; Lewis, G. R.; Dance, I. Angew. Chem.Int. Ed. 2002, 41, 275 - 277. (d) Lee, J. W.; Samal, S.; Selvapalam, N.; Kim, H.-J.; Kim, K. Acc.Chem.Res. 2003, 36, 621 - 630.

(e) Liu, S.; Zavalij, P. Y.; Isaacs, L. L.Am.Chem.Soc. 2005, 127, 16798 - 16799.

Saenger, W. Angew. Chem.Int.Ed. 1980, 19, 344 - 362.

(18) (a) Ashton, P. R.; Menzer, S.; Raymo, F. M.; Shimizu, G. K. H.; Stoddart, J. F.; Williams, D. J. Chem. Commun. 1996, 487 - 490. (b) Asakawa, M.; Ashton, P. R.; Menzer, S.; Raymo, F. M.; Stoddart, J. F.; White, A. J. P.; Williams, D. J. Chem.Eur.J. 1996, 2, 877 -893 .

(19) (a) Ashton, P. R.; Brown, C. L.; Chrystal, E. J. T.; Goodnow, T. T.; Kaifer, A. E.; Parry, K. P.; Slawin, A. M. Z.; Spencer, N.; Stoddart, J. F.; Williams, D. J. Angew. Chem. Int. Ed. 1991, 30, 1039 - 1042. (b) Spruell, J. M.; Coskun, A.; Friedman, D. C.; Forgan, R. S.; Sarjeant, A. A.; Trabolsi, A.; Fahrenbach, A. C.; Barin, G.; Paxton, W. F.; Dey, S. K.; Olson, M. A.; Benítez, D.; Tkatchouk, E.; Colvin, M. T.; Carmielli, R.; Caldwell, S. T.; Rosair, G. M.; Hewage, S. H.; Duclairoir, F.; Seymour, J. L.; Slawin, A. M. Z.; Goddard, W. A. III, Wasielewski, M. R.; Cooke, G.; Stoddart, J. F. Nat. Chem. 2010, 2, 870 - 879. (c) Forgan, R. S.; Wang, C.; Friedman, D. C.; Spruell, J. M.; Stern, C. L.; Sarjeant, A. A.; Cao, D.; Stoddart, J. F. Chem.Eur._. 2012, 18, 202 - 212. 
(20) (a) Amabilino, D. B.; Ashton, P. R.; Bravo, J. A.; Raymo, F. M.; Stoddart, J. F.; White, A. J. P.; Williams, D. J. Eur. J. Org. Chem. 1999, 1295 - 1302. (b) Barin, G.; Coskun, A.; Friedman, D. C.; Olson, M. A.; Colvin, M. T.; Carmielli, R.; Dey, S. K.; Bozdemir, O. A.; Wasielewski, M. R.; Stoddart, J. F. Chem.Eur.J. 2011, 17, 213 - 222.

(a) Amabilino, D. B.; Ashton, P. R.; Boyd, S. E.; Lee, J. Y.; Menzer, S.; Stoddart, J. F.; Williams, D. J_Angew.Chem.Int.Ed. 1997, 36, 2070 - 2072. (b) Amabilino, D. B.; Ashton, P. R.; Balzani, V.; Boyd, S. E.; Credi, A.; Lee, J. Y.; Menzer, S.; Stoddart, J. F.; Venturi, M.; Williams, D. J. J.Am.Chem.Soc. 1998, 120, 4295 - 4307.

(22) Cheng, C.; Cheng, T.; Xiao, H.; Krzyaniak, M. D.; Wang, Y.; McGonigal, P. R.; Frasconi, M.; Barnes, J. C.; Fahrenbach, A. C.; Wasielewski, M. R.; Goddard, W. A. III, Stoddart, J. F. J.Am.Chem.Soc. 2016, 138, 8288 - 8300.

(23) (a) Zhu, Z.; Fahrenbach, A. C.; Li, H.; Barnes, J. C.; Lu, Z.; Dyar, S. M.; Zhang, H.; Lei, J.; Carmieli, R.; Sarjeant, A. A.; Stern, C. L.; Wasielewksi, M. R.; Stoddart, J. F. L.Am. Chem.Soc. 2012, 134, 11709 - 11720. (b) Sun, J.; Wu, Y.; Wang, Y.; Liu, Z.; Cheng, C.; Hartlieb, K. J.; Wasielewski, M. R.; Stoddart, J. F. L.Am.Chem.Soc. 2015, 137, 13484 13487.

(24) (a) Bruns, C. J.; Frasconi, M.; Iehl, J.; Hartlieb, K. J.; Schneebeli, S. T.; Cheng, C.; Stupp, S. I.; Stoddart, J. F. J.Am. Chem.Soc. 2014, 136, 4714 - 4723. (b) Wang, Y.; Frasconi, M.; Liu, W.-G.; Sun, J.; Wu, Y.; Nassar, M. S.; Botros, Y. Y.; Goddard, W. A. III; Wasielewski, M. R.; Stoddart, J. F. ACS Cent.Sci. 2016, 2, 89 - 98.

(25) Geuder, W.; Hünig, S.; Suchy, A. Tetrahedron 1986, 42, 1665 - 1677.

(26) Jeon, W. S.; Kim, H.-J.; Lee, C.; Kim, K. Chem. Commun. 2002, 1828 - 1829.

(27) (a) Barin, G.; Frasconi, M.; Dyar, S. M.; Iehl, J.; Buyukcakir, O.; Sarjeant, A. A.; Carmieli, R.; Coskun, A.; Wasielewski, M. R.; Stoddart, J. F. L.Am.Chem.Soc. 2013, 135, 2466 - 2469. (b) Berville, M.; Karmazin, L.; Wytko, J. A.; Weiss, J. Chem. Commun. 2015, $51,15772-15775$.

(28) The structure of $\mathbf{M S} \cdot 2 \mathrm{PF}_{6}$ has previously been determined by single crystal XRD (see reference 27a), and this structure was confirmed by XRD analysis of a new single crystal, though there are minor differences between the two structures. These small differences are discussed in the Supporting Information. The newly determined structure of $\mathbf{M S} \cdot 2 \mathrm{PF}_{6}$ is used for comparison with [MScm-CBPQT] $4 \mathrm{PF}_{6}$.

(29) Full details of DFT calculations are provided in the supporting information. 
(30) (a) Zhao, Y.; Truhlar, D.; Theor.Chem.Acc. 2008, 120, 215 - 241. (b) Zhao, Y.; Truhlar, D. Acc. Chem. Res. 2008, 41, $157-167$.

(31) (a) Krishnan, R.; Binkley, J. S.; Seeger, R.; Pople, J. A. L.Chem. Phvs. 1980, 72, 650 654. (b) McLean, A. D.; Chandler, G. S. L.Chem. Phvs. 1980, 72, 5639 - 5648. (c) Clark, T.; Chandrasekhar, J.; Spitznagel, G. W.; von Ragué Schleyer, P. J.Comput.Chem. 1983, 4, 294 - 301. (d) Frisch, M. J.; Pople, J. A.; Binkley, J. S. L.Chem. Phvs. 1984, 80, 3265 - 3269.

(32) (a) Grimme, S.; Antony, J.; Ehrlich, S.; Krieg, H. L.Chem. Phvs. 2010, 132, 154104. (b) Goerigk, L.; Grimme, S. Phvs. Chem. Chem. Phvs. 2011, 13, $6670-6688$.

(33) (a) Tannor, D. J.; Marten, B.; Murphy, R.; Friesner, R. A.; Sitkoff, D.; Nicholls, A.; Honig, B.; Ringnalda, M.; Goddard, W. A. III L_Am.Chem.Soc. 1994, 116, 11875 - 11882. (b) Marten, B.; Kim, K.; Cortis, C.; Friesner, R. A.; Murphy, R. B.; Ringnalda, M. N.; Sitkoff, D.; Honig, B. J.Phvs. Chem. 1996, 100, 11775 - 11788.

(34) Frasconi, M.; Fernando, I. R.; Wu, Y.; Liu, Z.; Liu, W.-G.; Dyar, S. M.; Barin, G.; Wasielewski, M. R.; Goddard, W. A. III, Stoddart, J. F. J.Am. Chem.Soc. 2015, 137, 11057 $-11068$.

(35) (a) Zhang, L.; Zhou, T.-Y.; Tian, J.; Wang, H.; Zhang, D.-W.; Zhao, X.; Liu, Y. Poly. Chem. 2014, 5, 4715-4721. (b) Zhou, C.; Tian, J.; Wang, J.; Zhang, D.; Zhao, X.; Liu, Y.; Li, Z.-T. Polv. Chem. 2014, 5, 341-345. (c) Wang, Y.; Frasconi, M.; Liu, W.-G.; Liu, Z.; Sarjeant, A. A.; Nassar, M. S.; Botros, Y. Y.; Goddard, W. A. III,; Stoddart, J. F. L.Am. Chem.Soc. 2015, 137, 876 - 885. (d) Tian, J.; Zhang, K-D.; Ding, Y.-D.; Wang, H.; Zhang, D.*; Hou, J-L.; Liu, Y.; Li, Z-T. Chem.Eur.J. 2014, 20, 575-584. (e) Wang, W-K.; Chen, Y-Y.; Wang, H.; Zhang, D-W.; Liu, Y.; Li, Z-T. Chem.Asian_J. 2014, 9, 1039-1044. 


\title{
Titles of Schemes
}

\author{
Scheme 1. Host-Guest Chemistry of Viologen-Based Cyclophanes \\ Scheme 2. Assessment of Radical Guests for the Diradical Host $\mathbf{M S}^{2(+\bullet)}$
}

\section{Captions to Figures}

\begin{abstract}
Figure 1. UV-Vis-NIR Spectra of $\boldsymbol{m}$-CBPQT ${ }^{2(+\bullet)}, \mathbf{M S}^{2(+\bullet)}$, and a 1:1 molar ratio mixture of $\boldsymbol{m}$ CBPQT $^{2(+\bullet)}$ and $\mathbf{M S}^{2(+\bullet)}$. Spectra were recorded in $\mathrm{MeCN}$ in a 1-mm path cuvette and $0.50 \mathrm{mM}$ concentration of the cyclophane(s).
\end{abstract}

Figure 2. a) UV-Vis-NIR Spectrophotometric monitoring of the titration of a solution of $\boldsymbol{m}$ CBPQT $^{2(+\bullet)}(0.050 \mathrm{mM}$ in $\mathrm{MeCN})$ with $\mathbf{M S}^{2(+\bullet)}$ in a $1 \mathrm{~cm}$ path cuvette. b) UV-Vis-NIR Data recorded on a 1:1 molar ratio mixture of $\boldsymbol{m}$-CBPQT ${ }^{2(+\bullet)}$ and $\mathbf{M S}^{\mathbf{2 ( + \bullet )}}(0.050 \mathrm{mM}$ each in $\mathrm{MeCN})$ at temperatures from $5-60{ }^{\circ} \mathrm{C}$ in a $1-\mathrm{cm}$ path cuvette.

Figure 3. Solid-state superstructures of $[\mathrm{MS} \subset \boldsymbol{m}-\mathbf{C B P Q T}]^{4(+\bullet)}$ depicted with combinations of tubular and space-filling representations. The $\mathbf{m}$-CBPQT ${ }^{2(+\bullet)}$ guest is highlighted in purple and the $\mathbf{M S}^{2(+\bullet)}$ host in blue. The tetracationic complex was crystallized as its $\mathrm{PF}_{6}{ }^{-}$salt, and the $\mathrm{PF}_{6}{ }^{-}$ counterions are omitted for the sake of clarity. The viologen units of the $\mathbf{M S}^{\mathbf{2}(+\bullet)}$ host can be identified by their close contacts with the viologen units of the $\mathbf{m}-\mathbf{C B P Q T}^{\mathbf{2}(+\bullet)}$ guest, and by the smaller dihedral angles observed between the pyridinium groups of each viologen unit than are observed between the phenylene groups of the biphenylene linkers. Two distinct co-conformers 
of $[\mathbf{M S} \subset \boldsymbol{m}-\mathbf{C B P Q T}]^{4(+\bullet)}$ were located in the unit cell and both are presented: $\left.\mathbf{a}-\mathbf{c}\right)[\mathbf{M S} \subset \boldsymbol{m}$ CBPQT $^{4(+\bullet)}$ featuring the $\boldsymbol{m}$-CBPQT ${ }^{2(+\bullet)}$ guest in a linear conformation. $\left.\mathbf{d}-\mathbf{e}\right)[\mathbf{M S} \subset \boldsymbol{m}$ CBPQT $]^{4(+\bullet)}$ featuring the chair-like conformation of the $\boldsymbol{m}$-CBPQT ${ }^{2(+\bullet)}$ guest.

Figure 4. Solid-state structure of $\boldsymbol{m}$-CBPQT $\mathbf{T}^{\mathbf{2}(+)}$ depicted with combinations of tubular and space-filling representations. The dicationic cyclophane was crystallized as its $\mathrm{PF}_{6}{ }^{-}$salt, and the $\mathrm{PF}_{6}{ }^{-}$counterions are omitted for the sake of clarity. Two distinct conformers of $\boldsymbol{m}$-CBPQT $\mathbf{C}^{\mathbf{2}(\bullet)}$ were located in the unit cell and both are presented: a) Chair conformer of $\mathbf{m}-\mathbf{C B P Q T}^{\mathbf{2}\left({ }^{\bullet}\right)}$ viewed with the four nitrogen atoms in the plane of the page. b) Chair conformer of $\boldsymbol{m}$-CBPQT $\mathbf{C}^{\mathbf{2}+\bullet}$ viewed with the viologen units parallel to the page. c) Linear conformer of $\boldsymbol{m}$-CBPQT $\mathbf{C H}^{\mathbf{2}+\bullet}$ viewed with the four nitrogen atoms in the plane of the page. d) Linear conformer of $\boldsymbol{m}$ CBPQT $^{2(+\bullet)}$ viewed with the viologen units parallel to the page.

Figure 5. Comparison of the solid-state (super)structures of $\mathbf{M S}^{\mathbf{2 ( + \bullet}},[\mathbf{M S} \subset \mathbf{m}-\mathbf{C B P Q T}]^{4(+\bullet)}$, and m-CBPQT $\mathbf{T}^{2(+\bullet)}$ depicted with tubular and space-filling representations. All cationic compounds were crystallized as their $\mathrm{PF}_{6}{ }^{-}$salts, and the $\mathrm{PF}_{6}{ }^{-}$counterions are omitted for the sake of clarity. $\mathbf{M S}^{2(+\bullet)}$ is highlighted in blue and $\boldsymbol{m}$-CBPQT $\mathbf{T}^{\mathbf{2 ( + \bullet}}$ is portrayed in purple and pink. a) Ideal alignment of $\mathbf{M S}^{\mathbf{2}(+\bullet)}$ in radical-paired columns within the solid-state superstructure. The squareshaped cavity of the cyclophane is occupied by two molecules of ${ }^{i} \operatorname{Pr}_{2} \mathrm{O}$. b) $[\mathrm{MS} \subset \boldsymbol{m}-\mathrm{CBPQT}]^{\mathbf{4 ( + )}}$ featuring the linear conformer of the $\boldsymbol{m}$-CBPQT $\mathbf{C}^{\mathbf{2}(+)}$ guest. c) $[\mathrm{MS} \subset \boldsymbol{m} \text {-CBPQT }]^{4(+\bullet)}$ featuring the chair conformer of the $\boldsymbol{m}$-CBPQT ${ }^{2(+\bullet)}$ guest. d) Poorly aligned column of the two co-conformations of $[\text { MScm-CBPQT }]^{4(+\bullet)}$ within the solid-state 
superstructure. e) Linear conformer of $\boldsymbol{m}-\mathbf{C B P Q T}^{\mathbf{2}(+\bullet)}$ viewed with the four nitrogen atoms in the plane of the page. f) Ideal alignment of the chair-like conformer of $\boldsymbol{m}$-CBPQT ${ }^{2(+\bullet)}$ in radicalpaired columns of the solid-state superstructure. $\mathbf{g})$ Solid-state superstructure of $\boldsymbol{m}$-CBPQT $\mathbf{C P}^{\mathbf{2}(+)}$. The chair-like conformation is portrayed in pink and the linear conformer is highlighted in purple. Counterions are omitted for the sake of clarity.

Figure 6. Optimized computational model (super)structures of $\mathbf{M S}^{\mathbf{2 ( + \bullet}} \mathbf{D F T}, \mathbf{m}-\mathbf{C B P Q T} \mathbf{T}^{\mathbf{2 ( + \bullet})}$ DFT, and $[\text { MS } \subset \text { m-CBPQT }]^{4(+\bullet)}$ DFT determined by DFT calculations at the M06-2X level including D3 van der Waals attraction and continuum solvation. Calculated interplanar distances and angles are provided in red, and the corresponding measurements from the solid-state structures are presented in blue in parenthesis. a) $\mathbf{M S}^{\mathbf{2 ( + \bullet )}}$ DFT. b) Linear conformation of $\boldsymbol{m - C B P Q T ^ { 2 ( + \bullet ) }}{ }^{\text {DFT. }}$ c) Chair-like conformation of $m-$ CBPQT $^{2(+\bullet)}$ DFT. d - e) $[\mathrm{MS} \subset m-\mathrm{CBPQT}]^{4(+\bullet)}$ DFT containing the linear conformation of the $\boldsymbol{m}$-CBPQT ${ }^{\mathbf{2}(+\bullet)}$ DFT guest. $\left.\mathbf{f}-\mathbf{g}\right)[\mathrm{MS} \boldsymbol{\text { C }} \text {-CBPQT }]^{4(+\bullet)}$ DFT containing the chair-like conformation of the $\boldsymbol{m}$-CBPQT $\mathbf{C}^{\mathbf{2 ( + \bullet}}$ DFT guest.

Figure 7. Frontier molecular orbitals of $[\mathrm{MS} \subset \boldsymbol{m}-\mathrm{CBPQT}]^{\mathbf{4 ( + \bullet )}}$ DFT determined by DFT calculations. Orbital energies are provided in parentheses in units of hartrees. a) HOMO. b) HOMO-1. c) LUMO.

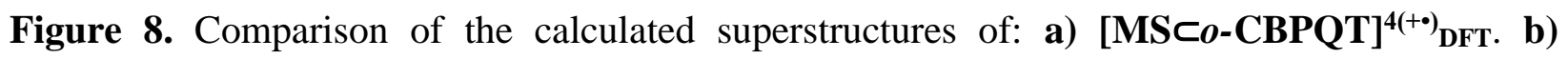
$[\mathrm{MS} \subset m-\mathrm{CBPQT}]^{4(+\bullet)}$ DFT. c) $[\mathrm{MS} \subset \mathrm{CBPQT}]^{4(+\bullet)}$ DFT. 
Figure 9. a) Relative integrated EPR signal intensities of $0.50 \mathrm{mM}$ solutions of $\mathbf{M S} \cdot 2 \mathrm{PF} 6, \boldsymbol{m}$ $\mathrm{CBPQT} \cdot 2 \mathrm{PF}_{6}, \boldsymbol{o}-\mathrm{CBPQT} \bullet 2 \mathrm{PF}_{6}$, and a mixture of $\mathrm{MS} \bullet 2 \mathrm{PF}_{6}$ and $\boldsymbol{m}-\mathrm{CBPQT} \cdot 2 \mathrm{PF}_{6}$ in $\mathrm{MeCN}$ at 298 K. b) EPR spectra recorded from $-30-70{ }^{\circ} \mathrm{C}$ on a mixture of $\mathrm{MS} \cdot 2 \mathrm{PF} 6$ and $\boldsymbol{m}$ CBPQT•2PF 6 (0.45 $\mathrm{mM}$ each) in $\mathrm{MeCN}$.

Figure 10. Cyclic voltammograms of: a) $\mathbf{M S}^{4+}(0.05 \mathrm{mM})$, b) $\boldsymbol{m}-\mathbf{C B P Q T}^{4+}(0.05 \mathrm{mM})$, and c) a 1:1 molar ratio mixture of $\mathbf{M S}^{\mathbf{4 +}}$ and $\boldsymbol{m}$-CBPQT ${ }^{4+}$ (0.05 $\mathrm{mM}$ each). CVs were recorded in a 0.1 $\mathrm{M}$ solution of $\mathrm{Bu}_{4} \mathrm{NPF}_{6}$ electrolyte in $\mathrm{MeCN}$ at a $0.2 \mathrm{~V} / \mathrm{s}$ scan rate, and are referenced to the reversible $\mathrm{Fc} / \mathrm{Fc}^{+}$couple $([$ferrocene $]=0.04 \mathrm{mM})$, which exhibited $\Delta E_{\mathrm{p}}=69 \mathrm{mV}(\mathbf{a}), 67 \mathrm{mV}(\mathbf{b})$, and $65 \mathrm{mV}(\mathbf{c})$.

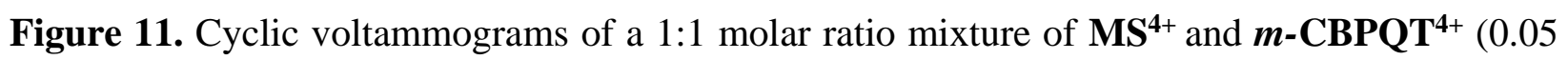
$\mathrm{mM}$ each) in $0.1 \mathrm{M} \mathrm{Bu} 4 \mathrm{NPF}_{6}$ in $\mathrm{MeCN}$ with potentials referenced to an internal standard of ferrocene $(0.04 \mathrm{mM})$. The voltammograms are truncated to focus on the scan rate dependent behavior of the $\left(\mathrm{MS}^{4+}+m-\mathrm{CBPQT}^{4+}\right) /[\mathrm{MS} \subset \boldsymbol{m}-\mathrm{CBPQT}]^{4(+\bullet)}$ redox couple. Arrows mark select changes in peaks relative to the preceding $\mathrm{CV}$. The $\Delta \mathrm{E}_{\mathrm{p}}$ values for the $\mathrm{Fc} / \mathrm{Fc}^{+}$redox couple (not visible in the truncated CVs) are: a) $\Delta E_{\mathrm{p}(\mathrm{Fc} / \mathrm{Fc}+)}=102 \mathrm{mV} / \mathrm{s}$ at $0.025 \mathrm{~V} / \mathrm{s}$, b) $\Delta E_{\mathrm{p}(\mathrm{Fc} / \mathrm{Fc}+)}=67 \mathrm{mV} / \mathrm{s}$ at $0.1 \mathrm{~V} / \mathrm{s}$, c) $\Delta E_{\mathrm{p}\left(\mathrm{Fc} / \mathrm{Fc}^{+}\right)}=66 \mathrm{mV} / \mathrm{s}$ at $0.2 \mathrm{~V} / \mathrm{s}$, d) $\Delta E_{\mathrm{p}\left(\mathrm{Fc} / \mathrm{Fc}^{+}\right)}=62 \mathrm{mV} / \mathrm{s}$ at $\left.1 \mathrm{~V} / \mathrm{s}, \mathbf{e}\right) \Delta E_{\mathrm{p}\left(\mathrm{Fc} / \mathrm{Fc}^{+}\right)}=$ $67 \mathrm{mV} / \mathrm{s}$ at $5 \mathrm{~V} / \mathrm{s}$, and f) $\Delta E_{\mathrm{p}(\mathrm{Fc} / \mathrm{Fc}+)}=106 \mathrm{mV} / \mathrm{s}$ at $50 \mathrm{~V} / \mathrm{s}$. 


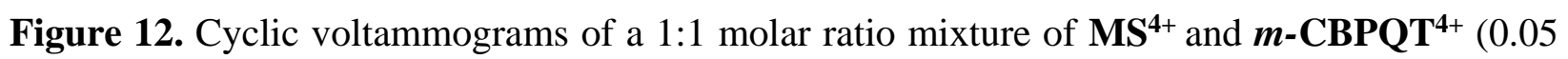
$\mathrm{mM}$ each) in $0.1 \mathrm{M} \mathrm{Bu} 4 \mathrm{NPF}_{6}$ in $\mathrm{MeCN}$ with potentials referenced to an internal standard of ferrocene $(0.04 \mathrm{mM})$. The $\Delta E_{\mathrm{p}}$ values for the $\mathrm{Fc} / \mathrm{Fc}^{+}$redox couple are: a) $\Delta E_{\mathrm{p}(\mathrm{Fc} / \mathrm{Fc}+)}=68 \mathrm{mV} / \mathrm{s}$ at $5 \mathrm{~V} / \mathrm{s}$. b) $\Delta E_{\mathrm{p}(\mathrm{Fc} / \mathrm{Fc}+)}=114 \mathrm{mV} / \mathrm{s}$ at $50 \mathrm{~V} / \mathrm{s}$. Arrows mark changes in the $\mathrm{CV}$ recoded at $50 \mathrm{~V} / \mathrm{s}(\mathbf{b})$ relative to the one recorded at $5 \mathrm{~V} / \mathrm{s}(\mathbf{a})$.

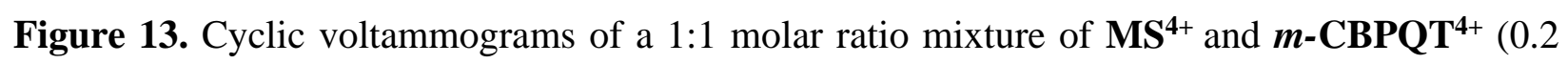
$\mathrm{mM}$ each) in $0.1 \mathrm{M} \mathrm{Bu} 4 \mathrm{NPF}_{6}$ in $\mathrm{MeCN}$ with potentials referenced to an internal standard of ferrocene $(0.16 \mathrm{mM})$. The $\Delta E_{\mathrm{p}}$ values for the $\mathrm{Fc} / \mathrm{Fc}^{+}$redox couple are: a) $\Delta E_{\mathrm{p}(\mathrm{Fc} / \mathrm{Fc}+)}=66 \mathrm{mV} / \mathrm{s}$ at $0.2 \mathrm{~V} / \mathrm{s}$. b) $\Delta E_{\mathrm{p}(\mathrm{Fc} / \mathrm{Fc}+)}=92 \mathrm{mV} / \mathrm{s}$ at $5 \mathrm{~V} / \mathrm{s}$. c) $\Delta E_{\mathrm{p}(\mathrm{Fc} / \mathrm{Fc}+)}=185 \mathrm{mV} / \mathrm{s}$ at $50 \mathrm{~V} / \mathrm{s}$. Arrows mark select changes in the $\mathrm{CV}$ recoded at $50 \mathrm{~V} / \mathrm{s}(\mathbf{c})$ relative to the one recorded at $5 \mathrm{~V} / \mathrm{s}(\mathbf{b})$. 


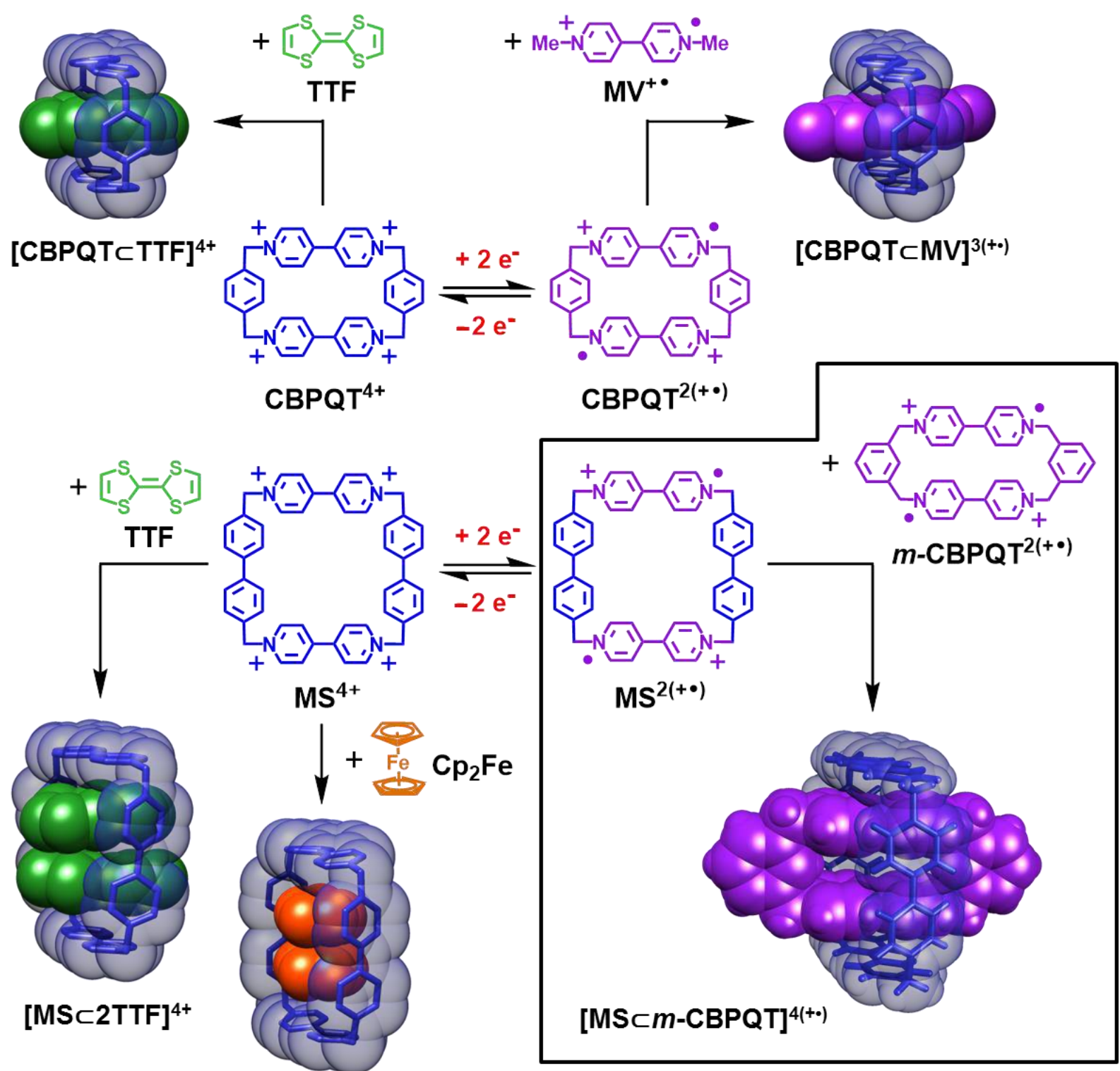

$\left[\mathrm{MS} \subset \mathrm{Cp}_{2} \mathrm{Fe}\right]^{4+}$

Scheme 1

Host-Guest Chemistry of Viologen-Based Cyclophanes 


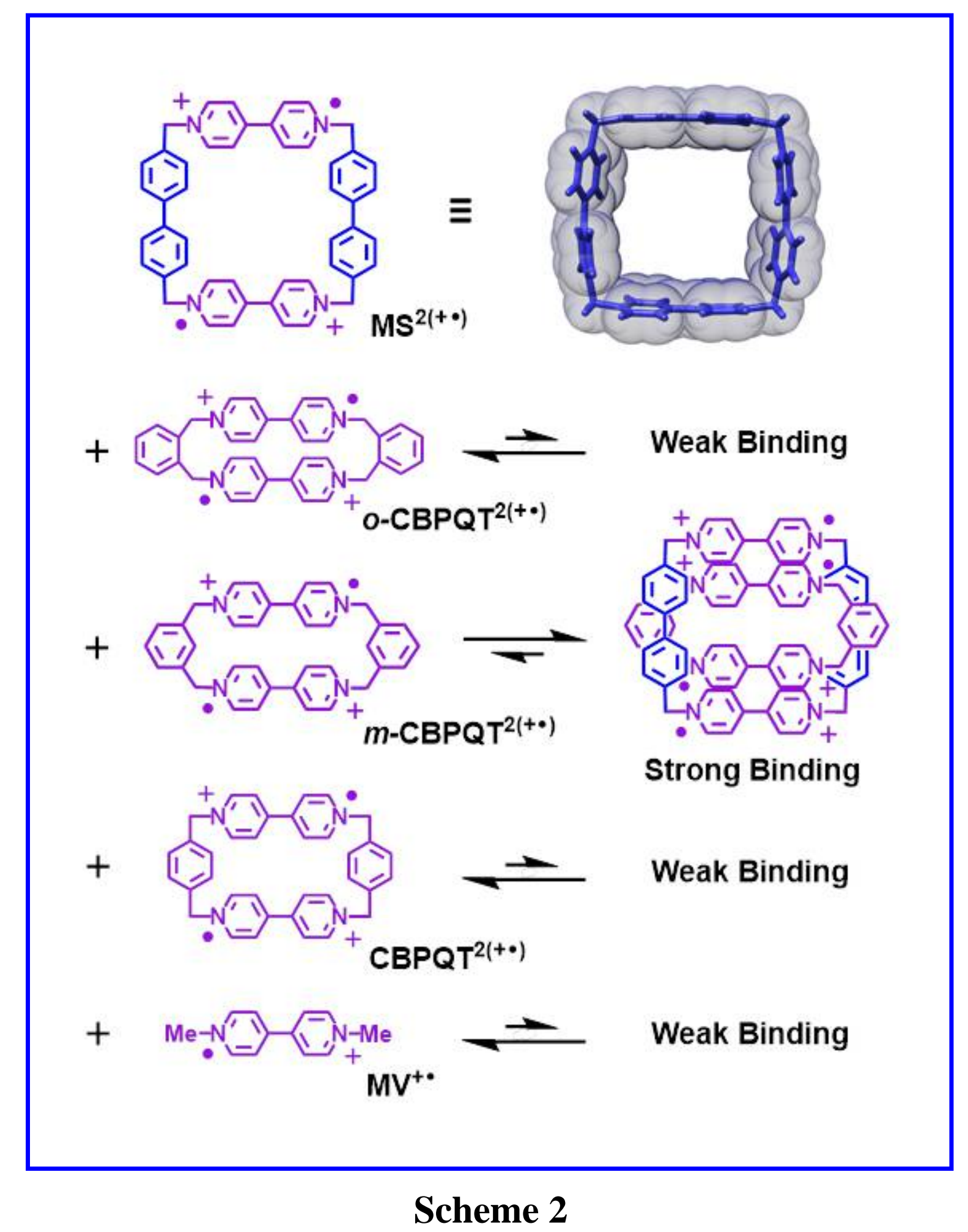

\section{Assessment of Radical Guests for the Diradical Host $\mathbf{M S}^{2(+\bullet)}$}




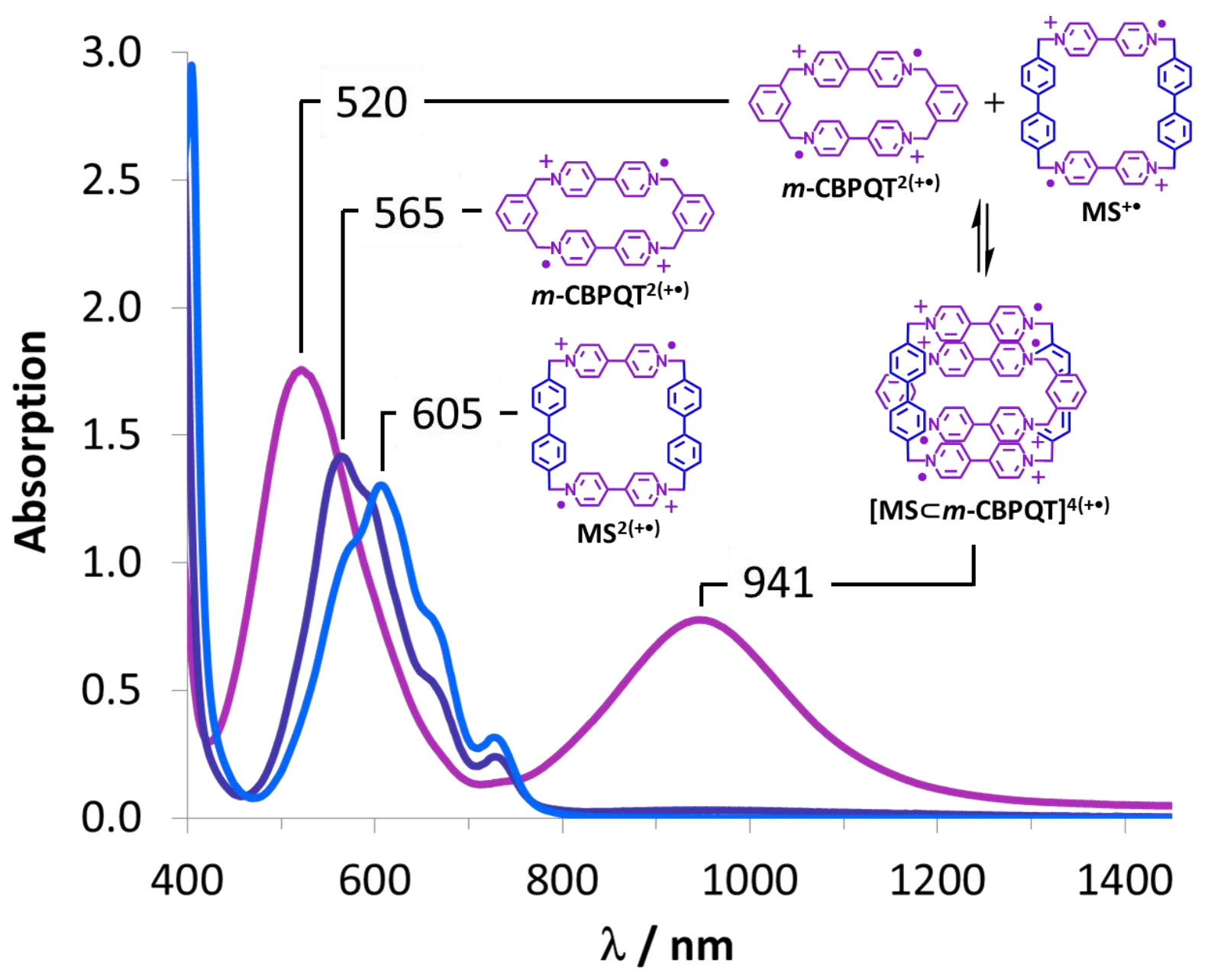

Figure 1

UV-Vis-NIR Spectra of $\boldsymbol{m}$-CBPQT $\mathbf{T}^{\mathbf{2 ( + \bullet}}, \mathbf{M S}^{\mathbf{2 ( + \bullet}}$, and a 1:1 molar ratio mixture of $\boldsymbol{m}$-CBPQT $\mathbf{C}^{\mathbf{2 ( + \bullet}}$ and MS $^{\mathbf{2 ( + \bullet}}$. Spectra were recorded in $\mathrm{MeCN}$ in a 1-mm path cuvette and $0.50 \mathrm{mM}$ concentration of the cyclophane(s). 


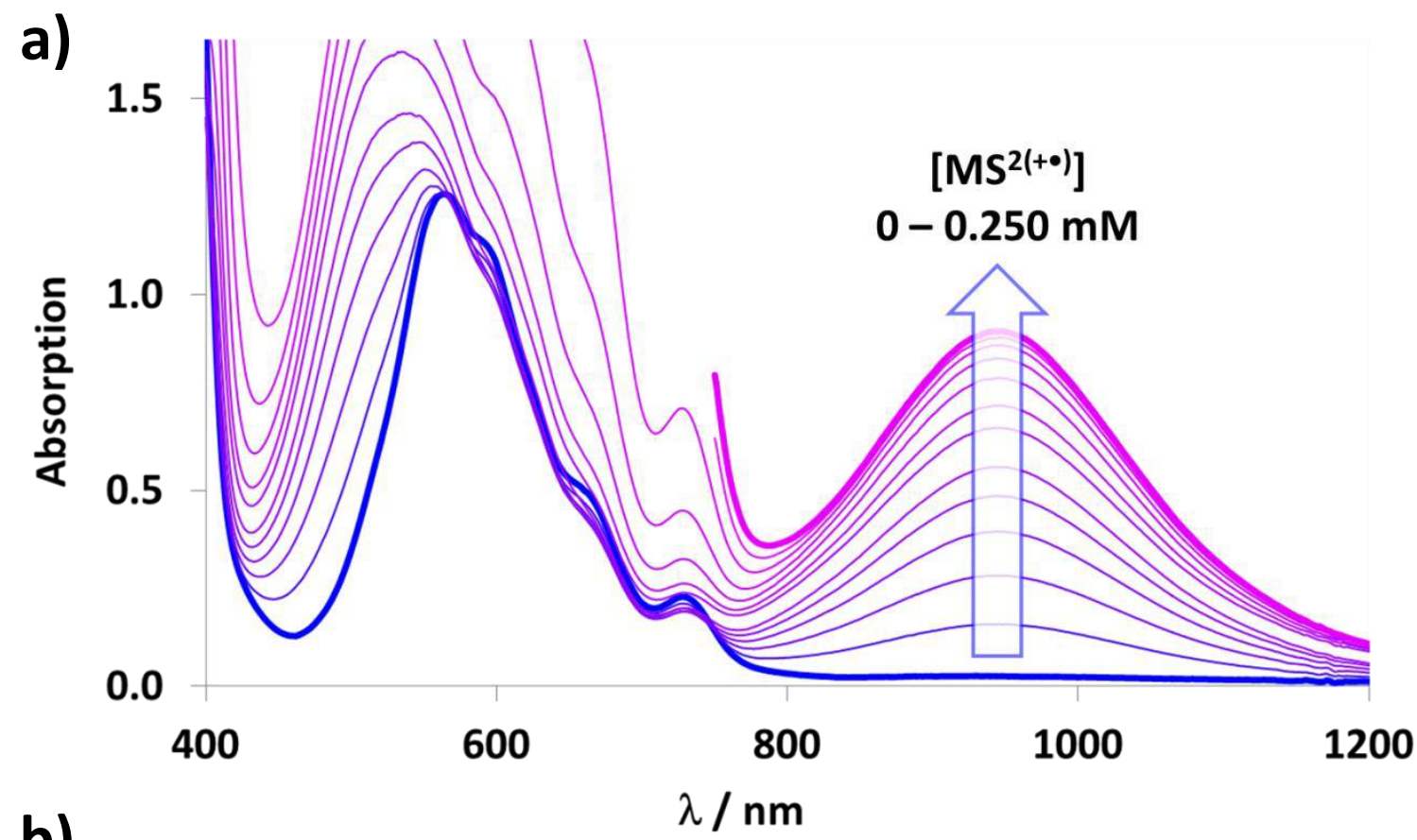

b)

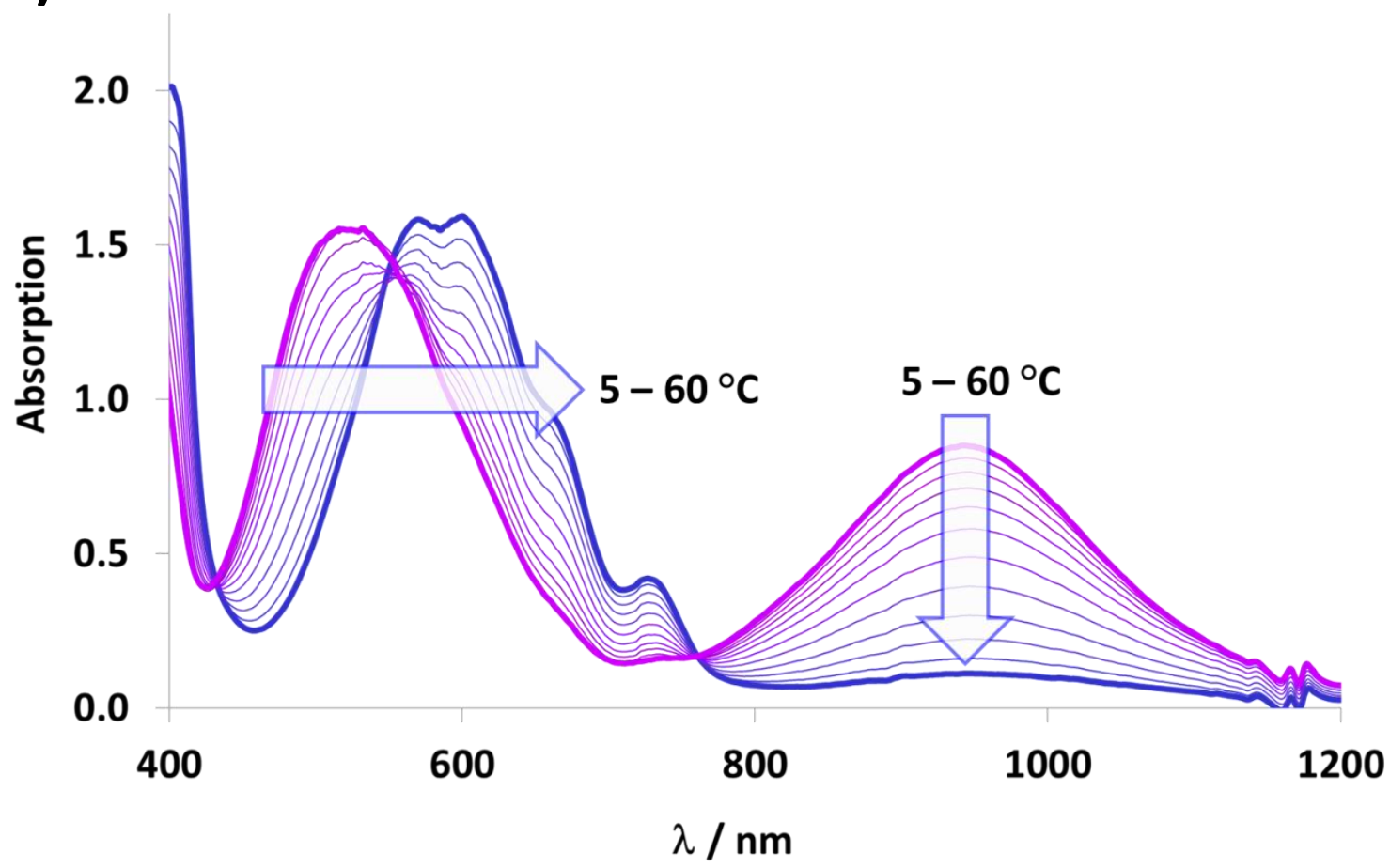

Figure 2

a) UV-Vis-NIR Spectrophotometric monitoring of the titration of a solution of $\boldsymbol{m}$-CBPQT $\mathbf{C H}^{\mathbf{( + \bullet})}$ $(0.050 \mathrm{mM}$ in $\mathrm{MeCN})$ with $\mathbf{M S}^{2(+)}$ in a $1 \mathrm{~cm}$ path cuvette. b) UV-Vis-NIR Data recorded on a 1:1 molar ratio mixture of $\boldsymbol{m}$-CBPQT ${ }^{2(+\bullet)}$ and $\mathbf{M S}^{\mathbf{2 ( + \bullet}}(0.050 \mathrm{mM}$ each in $\mathrm{MeCN})$ at temperatures from $5-60{ }^{\circ} \mathrm{C}$ in a $1-\mathrm{cm}$ path cuvette. 


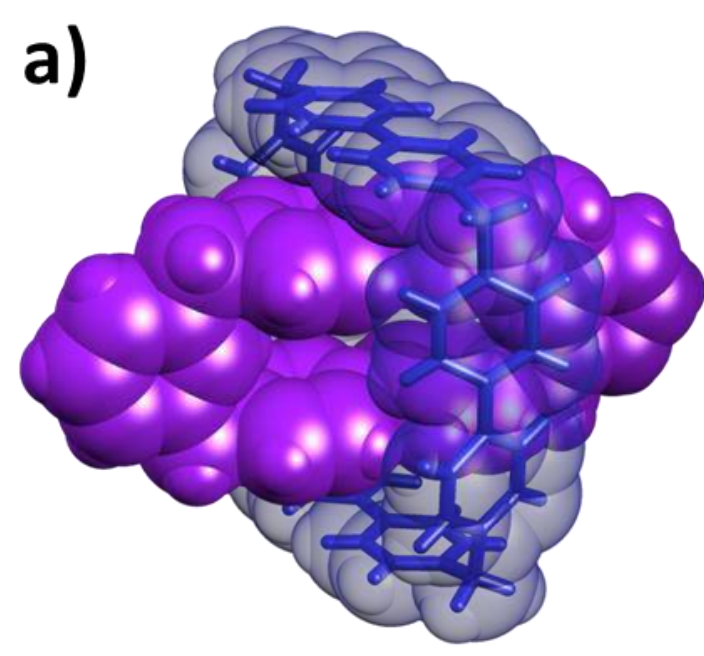

b)

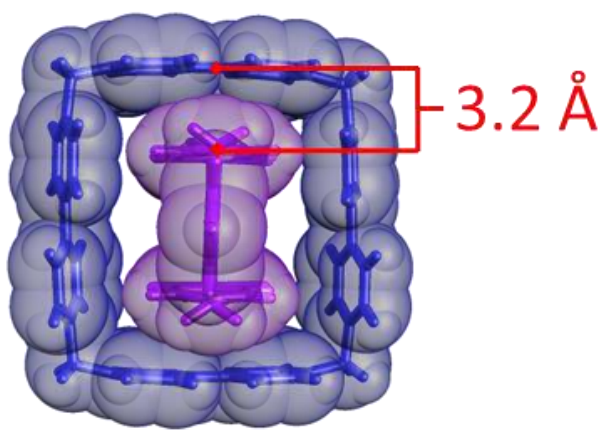

c)
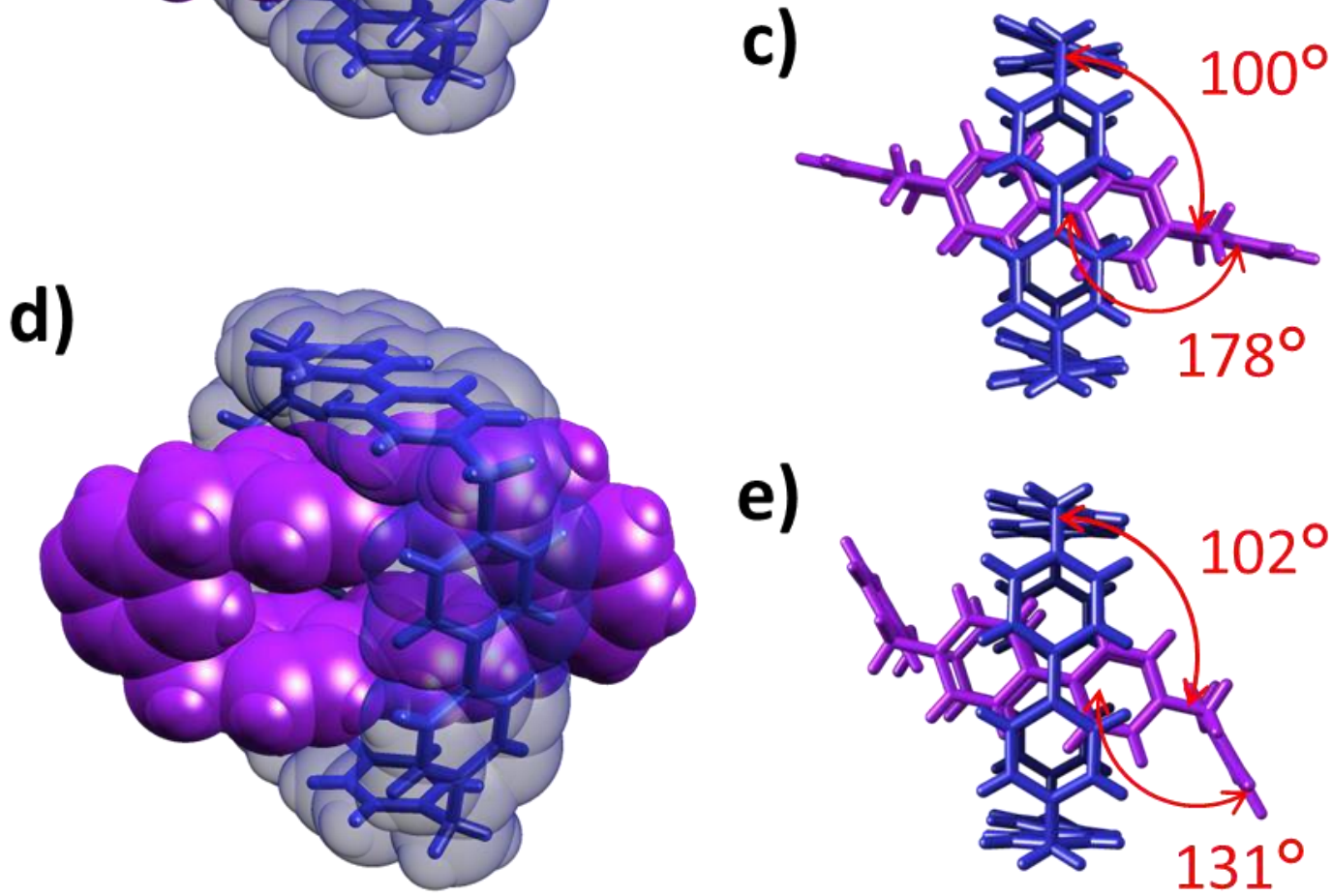

e)

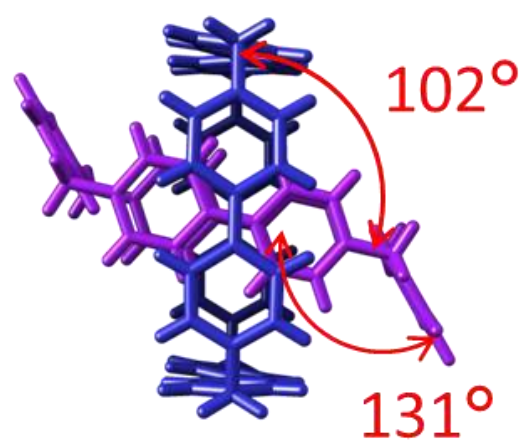

\section{Figure 3}

Solid-state superstructures of $[\mathbf{M S} \subset \boldsymbol{m} \text {-CBPQT }]^{4(+\bullet)}$ depicted with combinations of tubular and space-filling representations. The $\boldsymbol{m}$-CBPQT ${ }^{2(+\bullet)}$ guest is highlighted in purple and the $\mathbf{M S}^{2(+\bullet)}$ host in blue. The tetracationic complex was crystallized as its $\mathrm{PF}_{6}{ }^{-}$salt, and the $\mathrm{PF}_{6}{ }^{-}$counterions are omitted for the sake of clarity. The viologen units of the $\mathbf{M S}^{\mathbf{2 ( + \bullet})}$ host can be identified by their close contacts with the viologen units of the $\boldsymbol{m}$-CBPQT ${ }^{2(+)}$ guest, and by the smaller dihedral angles observed between the pyridinium groups of each viologen unit than are observed between the phenylene groups of the biphenylene linkers. Two distinct co-conformers of $[\mathbf{M S} \subset \boldsymbol{m} \text {-CBPQT }]^{4(+\bullet)}$ were located in the unit cell and both are presented: $\left.\mathbf{a}-\mathbf{c}\right)[\mathbf{M S} \subset \boldsymbol{m}$ CBPQT $^{4(+\bullet)}$ featuring the $\boldsymbol{m}$-CBPQT ${ }^{2(+\bullet)}$ guest in a linear conformation. d - e) $[\mathbf{M S} \subset \boldsymbol{m}$ CBPQT $]^{4(+\bullet)}$ featuring the chair-like conformation of the $\boldsymbol{m}$-CBPQT ${ }^{2(+\bullet)}$ guest. 
a)

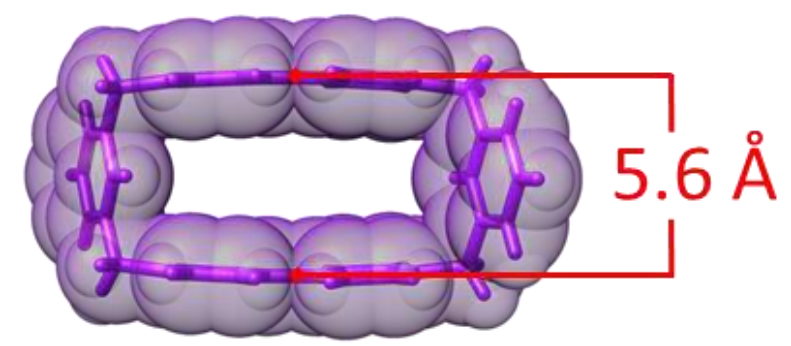

c)

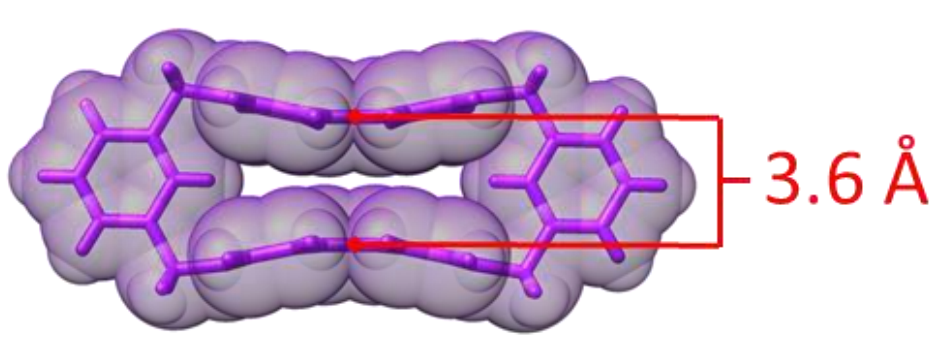

b)

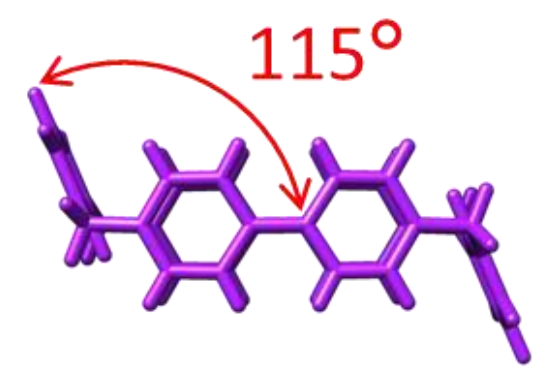

d)

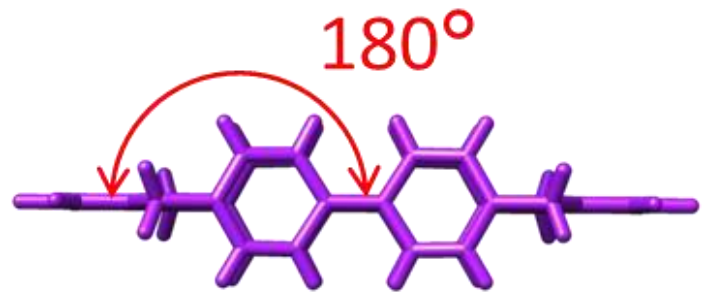

Figure 4

Solid-state structure of $\boldsymbol{m}$-CBPQT ${ }^{2(+\bullet)}$ depicted with combinations of tubular and space-filling representations. The dicationic cyclophane was crystallized as its $\mathrm{PF}_{6}{ }^{-}$salt, and the $\mathrm{PF}_{6}{ }^{-}$counterions are omitted for the sake of clarity. Two distinct conformers of $\boldsymbol{m}_{\text {-CBPQT }}{ }^{2(+)}$ were located in the unit cell and both are presented: a) Chair conformer of $\boldsymbol{m}$-CBPQT ${ }^{2(+\bullet)}$ viewed with the four nitrogen atoms in the plane of the page. b) Chair conformer of $\boldsymbol{m}$-CBPQT $\mathbf{C}^{\mathbf{2}\left({ }^{\bullet}\right)}$ viewed with the viologen units parallel to the page. c) Linear conformer of $\boldsymbol{m}$-CBPQT ${ }^{2(+\bullet)}$ viewed with the four nitrogen atoms in the plane of the page. d) Linear conformer of $\boldsymbol{m}$ CBPQT $^{2(+\bullet)}$ viewed with the viologen units parallel to the page. 

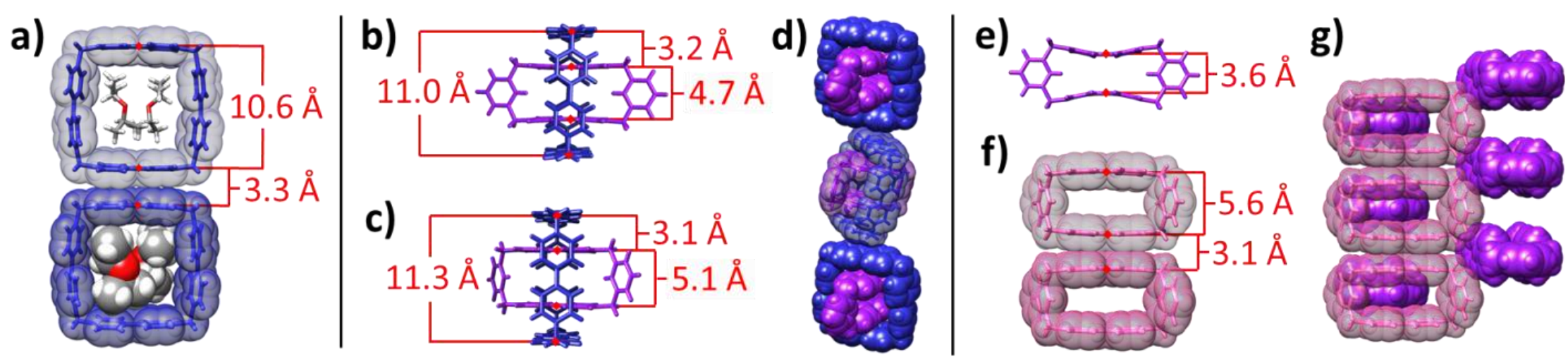

\section{Figure 5}

Comparison of the solid-state (super)structures of $\mathbf{M S}^{\mathbf{2}(+\bullet)},[\mathbf{M S} \subset \boldsymbol{m}-\mathbf{C B P Q T}]^{\mathbf{4 ( + \bullet}}$, and $\mathbf{m}-\mathbf{C B P Q T}^{\mathbf{2 ( + \bullet})}$ depicted with tubular and spacefilling representations. All cationic compounds were crystallized as their $\mathrm{PF}_{6}{ }^{-}$salts, and the $\mathrm{PF}_{6}{ }^{-}$counterions are omitted for the sake of clarity. $\mathbf{M S}^{\mathbf{2 ( + \bullet})}$ is highlighted in blue and $\mathbf{m}$-CBPQT $\mathbf{C}^{\mathbf{2}(\boldsymbol{\bullet})}$ is portrayed in purple and pink. a) Ideal alignment of $\mathbf{M S}^{\mathbf{2 ( + \bullet})}$ in radicalpaired columns within the solid-state superstructure. The square-shaped cavity of the cyclophane is occupied by two molecules of ${ }^{i} \operatorname{Pr}_{2} \mathrm{O}$. b) $[\mathrm{MS} \subset \boldsymbol{m} \text {-CBPQT}]^{4(+\bullet)}$ featuring the linear conformer of the $\boldsymbol{m}$-CBPQT ${ }^{2(+\bullet)}$ guest. c) $\left[\mathbf{M S} \subset \boldsymbol{m}\right.$-CBPQT] ${ }^{4(+\bullet)}$ featuring the chair conformer of the $\boldsymbol{m}$-CBPQT ${ }^{2(+\bullet)}$ guest. d) Poorly aligned column of the two co-conformations of $[\mathbf{M S} \subset \boldsymbol{m}-\mathbf{C B P Q T}]^{4(+\bullet)}$ within the solid-state superstructure. e) Linear conformer of $\mathbf{m - C B P Q T} \mathbf{T}^{\mathbf{2}+\bullet}$ viewed with the four nitrogen atoms in the plane of the page. f) Ideal alignment of the chair-like conformer of $\mathbf{m}$-CBPQT $\mathbf{C}^{\mathbf{2}+\bullet}$ in radical-paired columns of the solid-state superstructure. $\mathbf{g}$ ) Solid-state superstructure of $\boldsymbol{m}$-CBPQT $\mathbf{T}^{\mathbf{2}+\bullet}$. The chair-like conformation is portrayed in pink and the linear conformer is highlighted in purple. Counterions are omitted for the sake of clarity. 


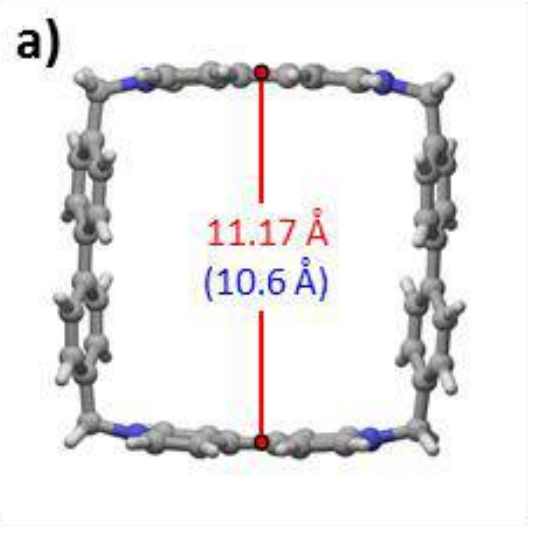

b)

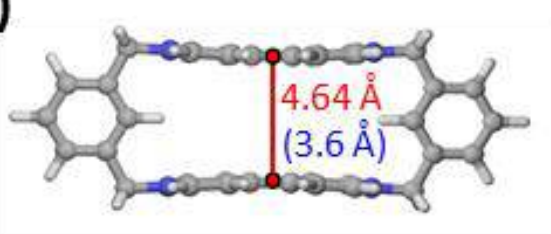

c)

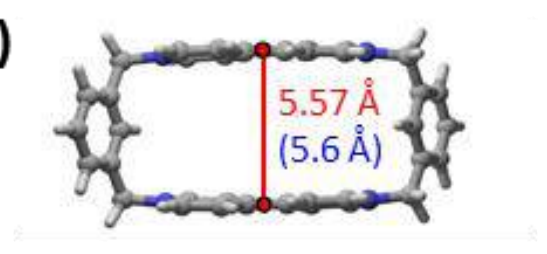

d)
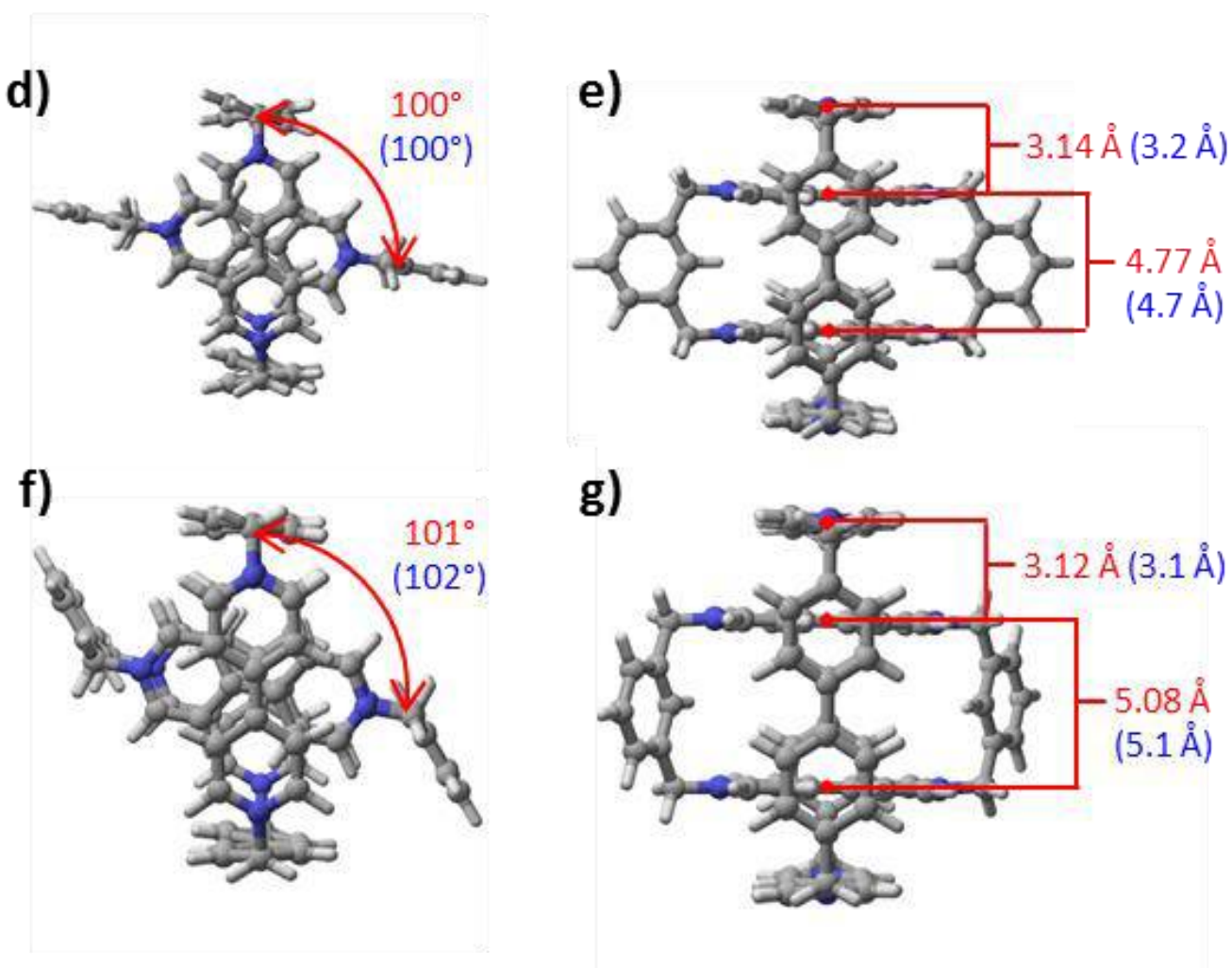

g)

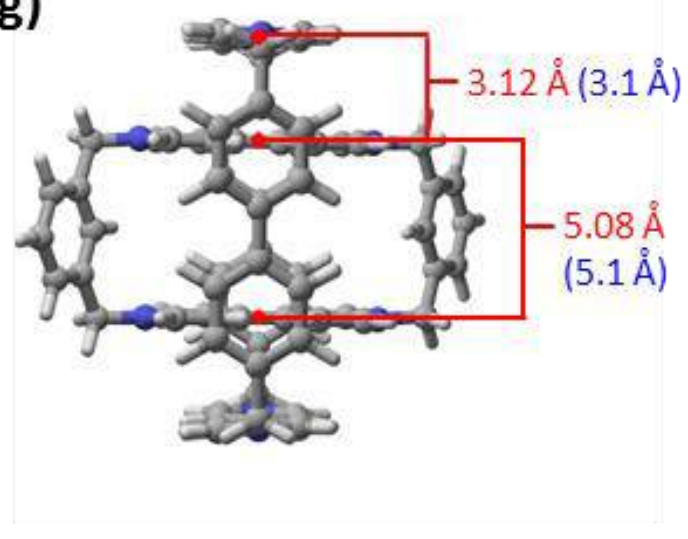

\section{Figure 6}

Optimized computational model (super)structures of $\mathbf{M S}^{2(+\cdot)}{ }_{\text {DFT }}, \boldsymbol{m}$-CBPQT $\mathbf{T}^{2(+\bullet)}$ DFT, and $[\text { MS } \subset \text { m-CBPQT }]^{4(+)}$ DFT determined by DFT calculations at the M06-2X level including D3 van der Waals attraction and continuum solvation. Calculated interplanar distances and angles are provided in red, and the corresponding measurements from the solid-state structures are presented in blue in parenthesis. a) $\mathbf{M S}^{2(+\circ)}$ DFT. b) Linear conformation of $\boldsymbol{m}$-CBPQT ${ }^{2(+\bullet)}$ DFT. c) Chair-like conformation of $m$-CBPQT ${ }^{2(+\bullet}$ DFT. d - e) $\left[\mathbf{M S} \subset \boldsymbol{m}\right.$-CBPQT] ${ }^{4(+\cdot)}{ }_{\text {DFT }}$ containing the linear conformation of the $m$-CBPQT ${ }^{2(+\cdot)}$ DFT guest. $\mathbf{f}-\mathrm{g}$ ) [MS $\boldsymbol{\text { [M-CBPQT] }}{ }^{4(+\bullet)}$ DFT containing the chair-like conformation of the $\boldsymbol{m}$-CBPQT ${ }^{2(+\bullet)}$ DFT guest. 
a)

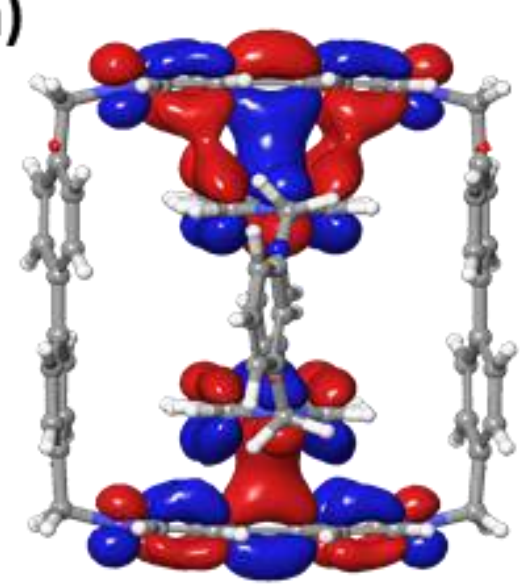

HOMO $(-0.48619)$ b)

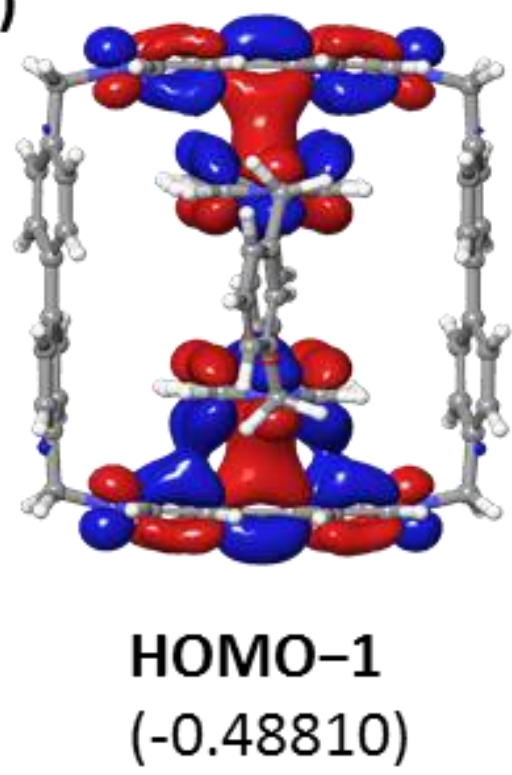

c)

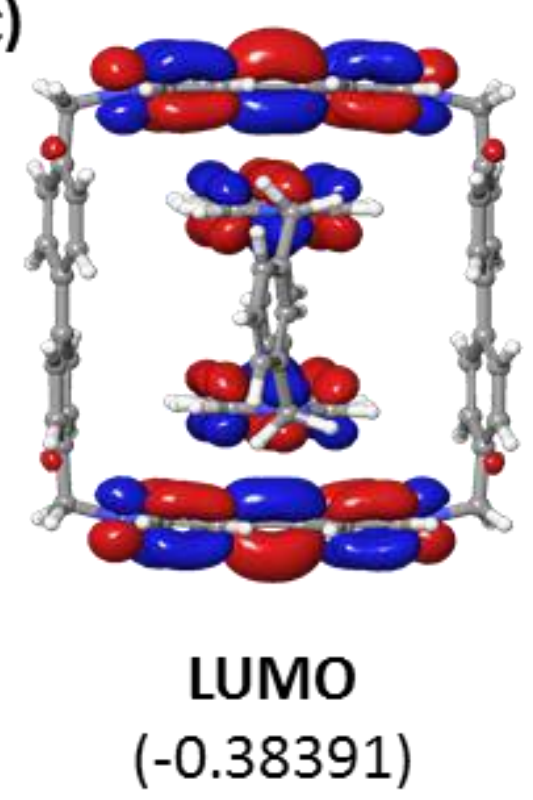

\section{Figure 7}

Frontier molecular orbitals of $[\mathbf{M S} \subset \boldsymbol{m}-\mathbf{C B P Q T}]^{4(+\bullet)}$ DFT determined by DFT calculations. Orbital energies are provided in parenthesis in units of hartrees. a) HOMO. b) HOMO-1. c) LUMO. 


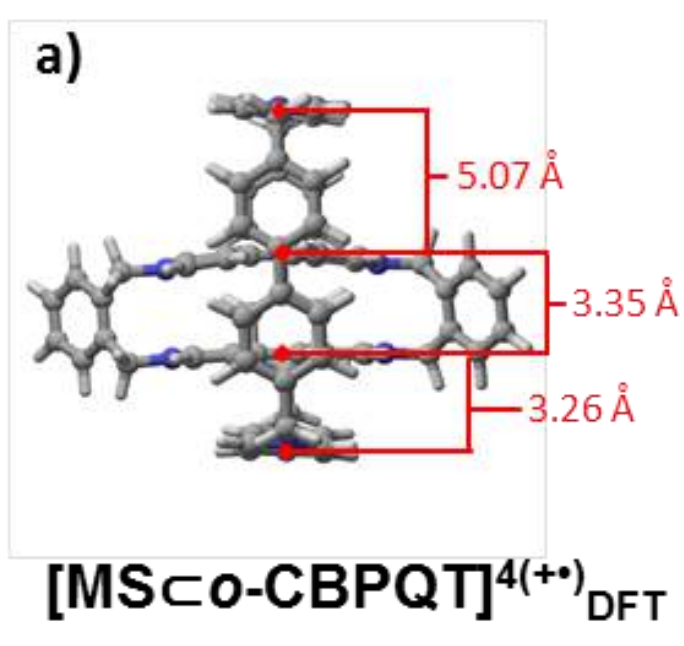

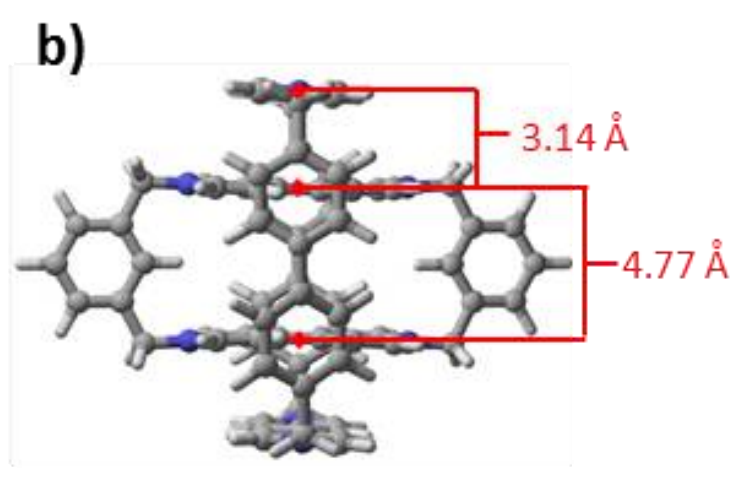

$[\mathrm{MS} \subset m-\mathrm{CBPQT}]^{4(+\cdot)} \mathrm{DFT}$

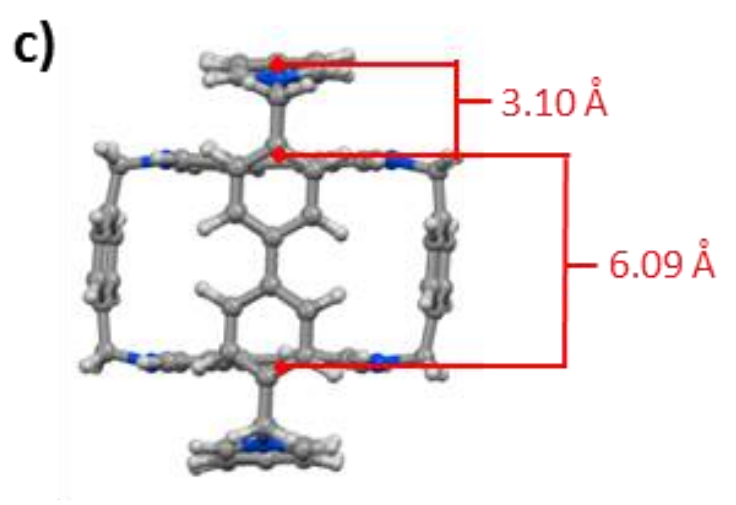

$[\mathrm{MS} \subset \mathrm{CBPQT}]^{4(+\cdot)}$ DFT

\section{Figure 8}

Comparison of the calculated superstructures of: a) $[\mathrm{MS} \subset \boldsymbol{o}-\mathrm{CBPQT}]^{4(+\bullet)}$ DFT. b) $[\mathrm{MS} \subset m-\mathrm{CBPQT}]^{4(+\bullet)}$ DFT. c) $[\mathrm{MS} \subset \mathrm{CBPQT}]^{4(+\bullet)}$ DFT. 

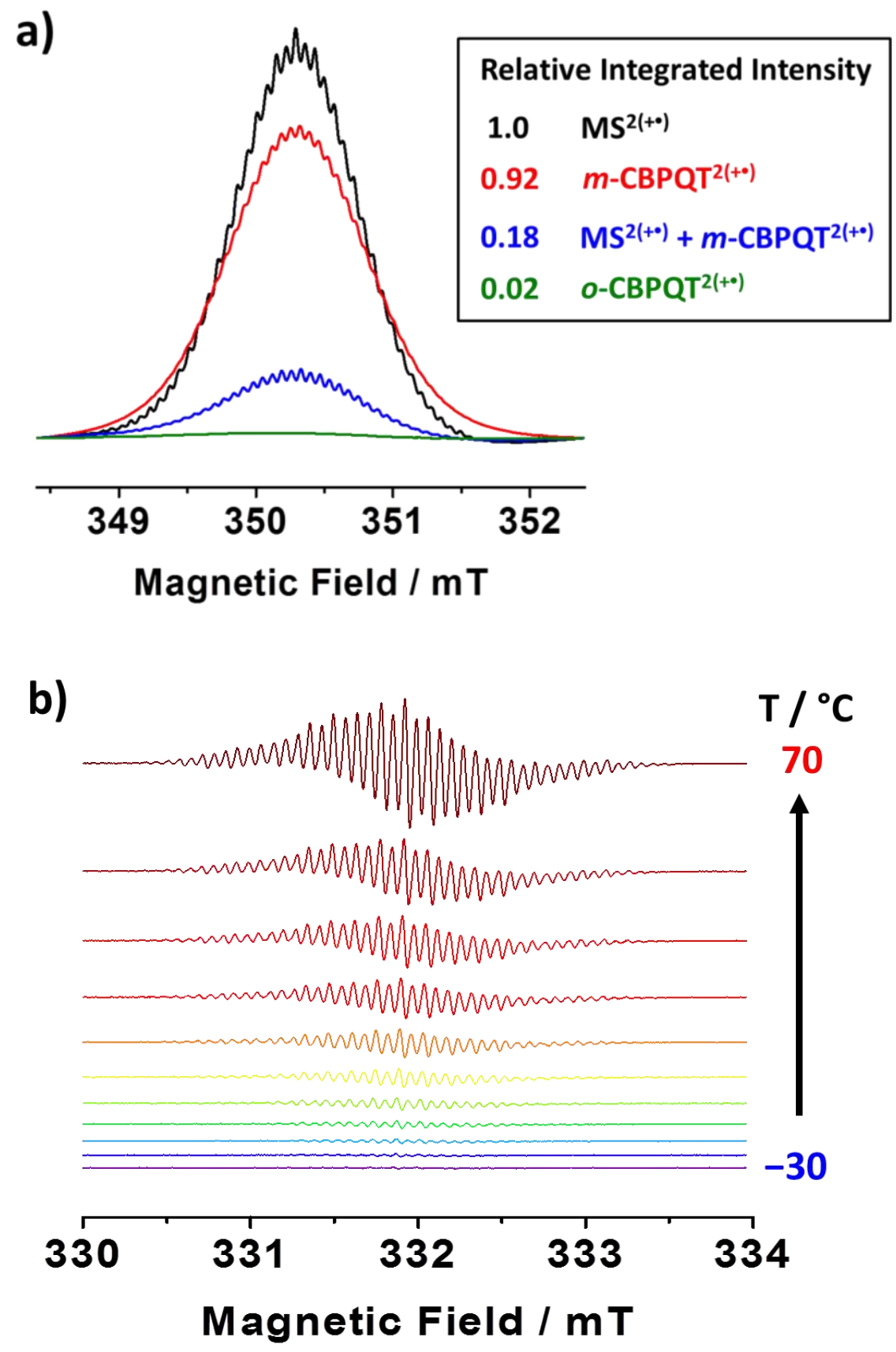

\section{Figure 9}

a) Relative integrated EPR signal intensities of $0.50 \mathrm{mM}$ solutions of $\mathbf{M S} \cdot 2 \mathrm{PF}_{6}, \boldsymbol{m}$ CBPQT•2PF 6 , $\boldsymbol{o}-\mathbf{C B P Q T} \cdot 2 \mathrm{PF}_{6}$, and a mixture of $\mathbf{M S} \bullet 2 \mathrm{PF}_{6}$ and $\boldsymbol{m}$-CBPQT•2PF6 in MeCN at 25 ${ }^{\circ} \mathrm{C}$. b) EPR spectra recorded from $-30-70{ }^{\circ} \mathrm{C}$ on a mixture of $\mathrm{MS} \cdot 2 \mathrm{PF}_{6}$ and $\boldsymbol{m}$-CBPQT•2PF 6 (0.45 mM each) in MeCN. 


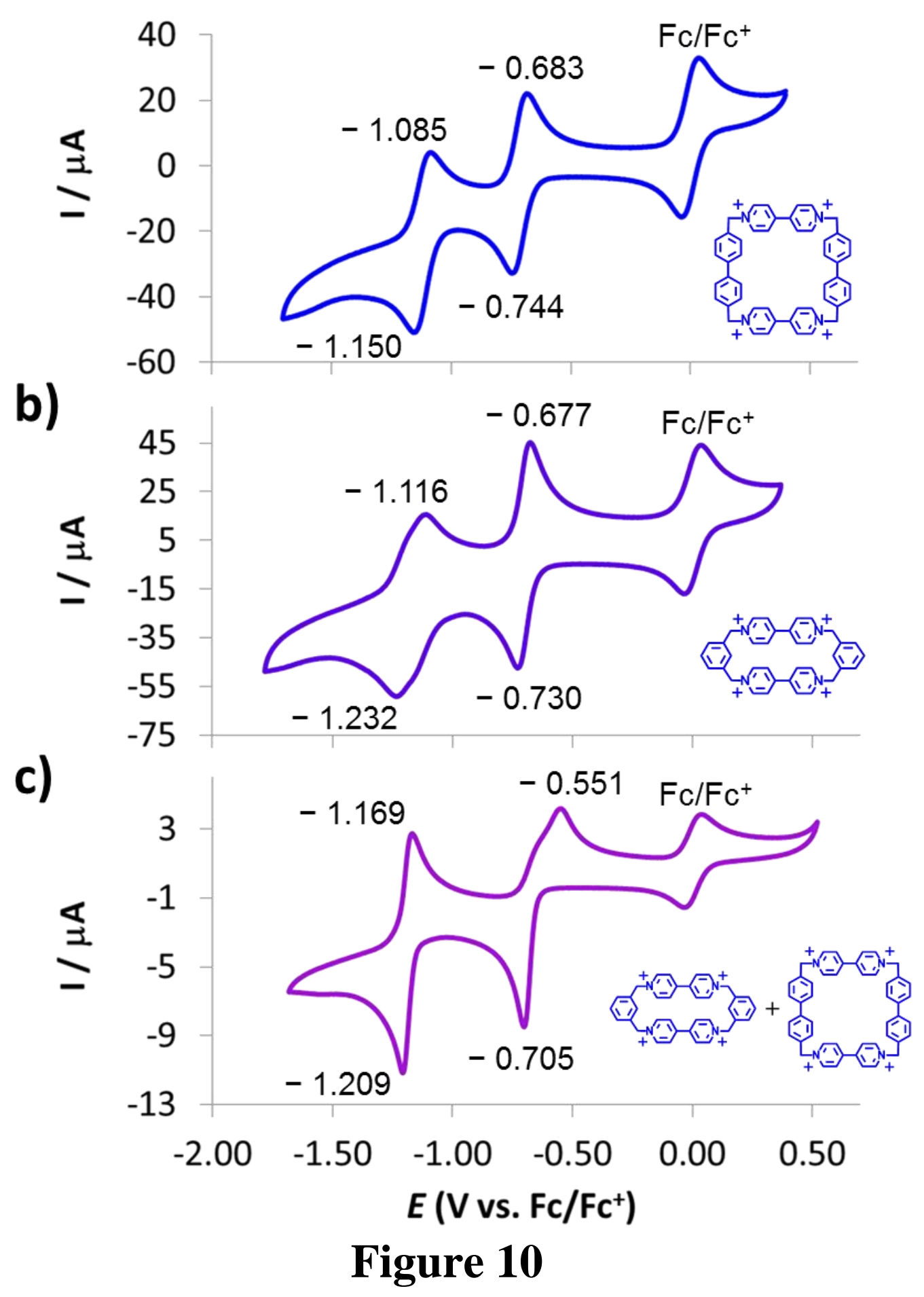

Cyclic voltammograms of: a) $\mathbf{M S}^{4+}(0.05 \mathrm{mM})$, b) $\boldsymbol{m}$-CBPQT ${ }^{4+}(0.05 \mathrm{mM})$, and c) a 1:1 molar

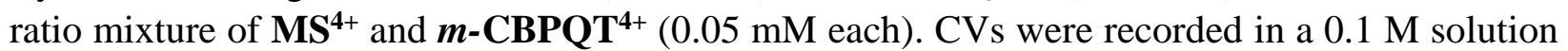
of $\mathrm{Bu}_{4} \mathrm{NPF}_{6}$ electrolyte in $\mathrm{MeCN}$ at a $0.2 \mathrm{~V} / \mathrm{s}$ scan rate, and are referenced to the reversible $\mathrm{Fc} / \mathrm{Fc}^{+}$couple $([$ferrocene $]=0.04 \mathrm{mM})$, which exhibited $\Delta \mathrm{E}_{\mathrm{p}}=69 \mathrm{mV}(\mathbf{a}), 67 \mathrm{mV}(\mathbf{b})$, and 65 $\mathrm{mV}(\mathbf{c})$. 

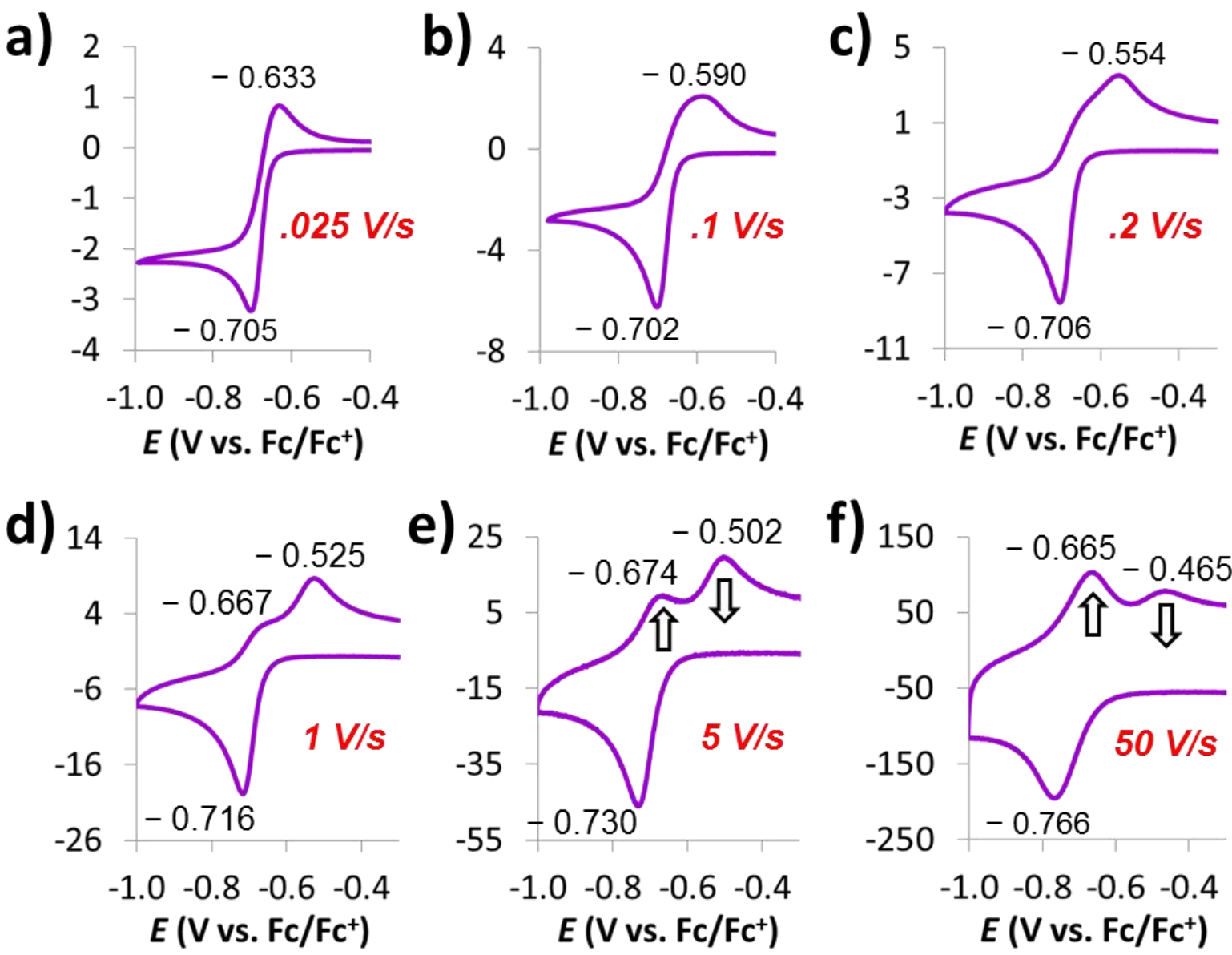

\section{Figure 11}

Cyclic voltammograms of a 1:1 molar ratio mixture of $\mathbf{M S}^{\mathbf{4 +}}$ and $\boldsymbol{m}$-CBPQT $\mathbf{C H}^{\mathbf{4}}(0.05 \mathrm{mM}$ each) in $0.1 \mathrm{M} \mathrm{Bu} 4 \mathrm{NPF}_{6}$ in $\mathrm{MeCN}$ with potentials referenced to an internal standard of ferrocene $(0.04$ $\mathrm{mM})$. The voltammograms are truncated to focus on the scan rate dependent behavior of the $\left(\mathrm{MS}^{4+}+\boldsymbol{m}\right.$-CBPQT $\left.{ }^{4+}\right) /[\mathrm{MS} \subset \boldsymbol{m}-\mathrm{CBPQT}]^{\mathbf{4 ( + )}}$ redox couple. Arrows mark select changes in peaks relative to the preceding $\mathrm{CV}$. The $\Delta \mathrm{E}_{\mathrm{p}}$ values for the $\mathrm{Fc} / \mathrm{Fc}^{+}$redox couple (not visible in the truncated CVs) are a) $\Delta \mathrm{E}_{\mathrm{p}(\mathrm{Fc} / \mathrm{Fc}+)}=102 \mathrm{mV} / \mathrm{s}$ at $0.025 \mathrm{~V} / \mathrm{s}$, b) $\Delta \mathrm{E}_{\mathrm{p}(\mathrm{Fc} / \mathrm{Fc}+)}=67 \mathrm{mV} / \mathrm{s}$ at 0.1 $\mathrm{V} / \mathrm{s}$, , c c) $\Delta \mathrm{E}_{\mathrm{p}(\mathrm{Fc} / \mathrm{Fc}+)}=66 \mathrm{mV} / \mathrm{s}$ at $0.2 \mathrm{~V} / \mathrm{s}$, d) $\Delta \mathrm{E}_{\mathrm{p}(\mathrm{Fc} / \mathrm{Fc}+)}=62 \mathrm{mV} / \mathrm{s}$ at $1 \mathrm{~V} / \mathrm{s}$, e) $\Delta \mathrm{E}_{\mathrm{p}(\mathrm{Fc} / \mathrm{Fc}+)}=67$ $\mathrm{mV} / \mathrm{s}$ at $5 \mathrm{~V} / \mathrm{s}$, and f) $\Delta \mathrm{E}_{\mathrm{p}(\mathrm{Fc} / \mathrm{Fc}+)}=106 \mathrm{mV} / \mathrm{s}$ at $50 \mathrm{~V} / \mathrm{s}$. 

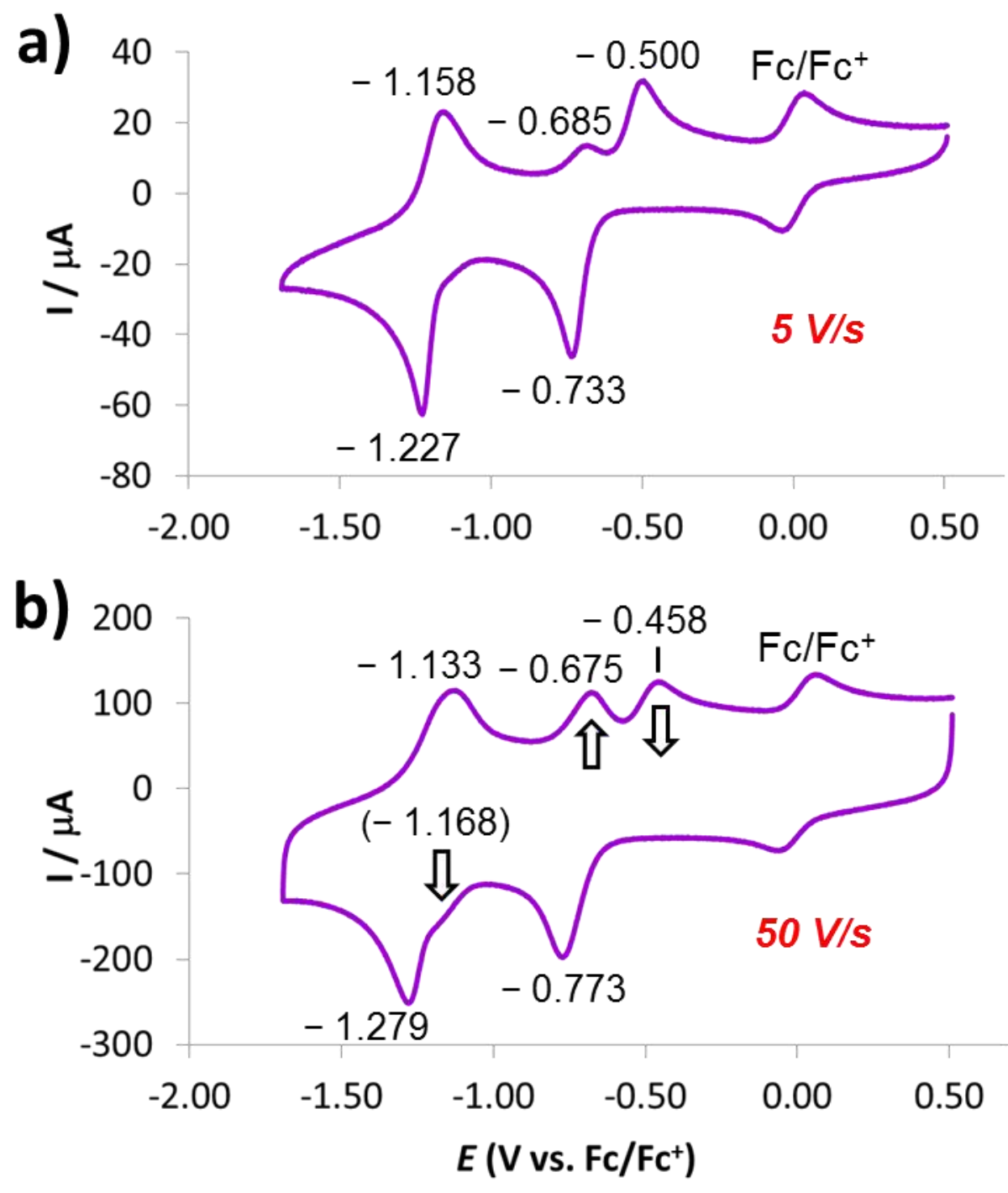

Figure 12

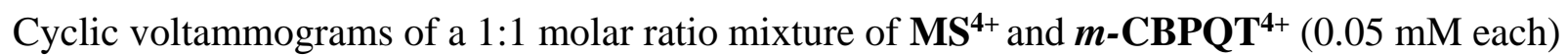
in $0.1 \mathrm{M} \mathrm{Bu} 4 \mathrm{NPF}_{6}$ in $\mathrm{MeCN}$ with potentials referenced to an internal standard of ferrocene $(0.04$ $\mathrm{mM})$. The $\Delta \mathrm{E}_{\mathrm{p}}$ values for the $\mathrm{Fc} / \mathrm{Fc}^{+}$redox couple are: a) $\Delta \mathrm{E}_{\mathrm{p}(\mathrm{Fc} / \mathrm{Fc}+)}=68 \mathrm{mV} / \mathrm{s}$ at $5 \mathrm{~V} / \mathrm{s}$. b) $\Delta \mathrm{E}_{\mathrm{p}(\mathrm{Fc} / \mathrm{Fc}+)}=114 \mathrm{mV} / \mathrm{s}$ at $50 \mathrm{~V} / \mathrm{s}$. Arrows mark changes in the $\mathrm{CV}$ recoded at $50 \mathrm{~V} / \mathrm{s}$ (b) relative to the one recorded at $5 \mathrm{~V} / \mathrm{s}(\mathbf{a})$. 


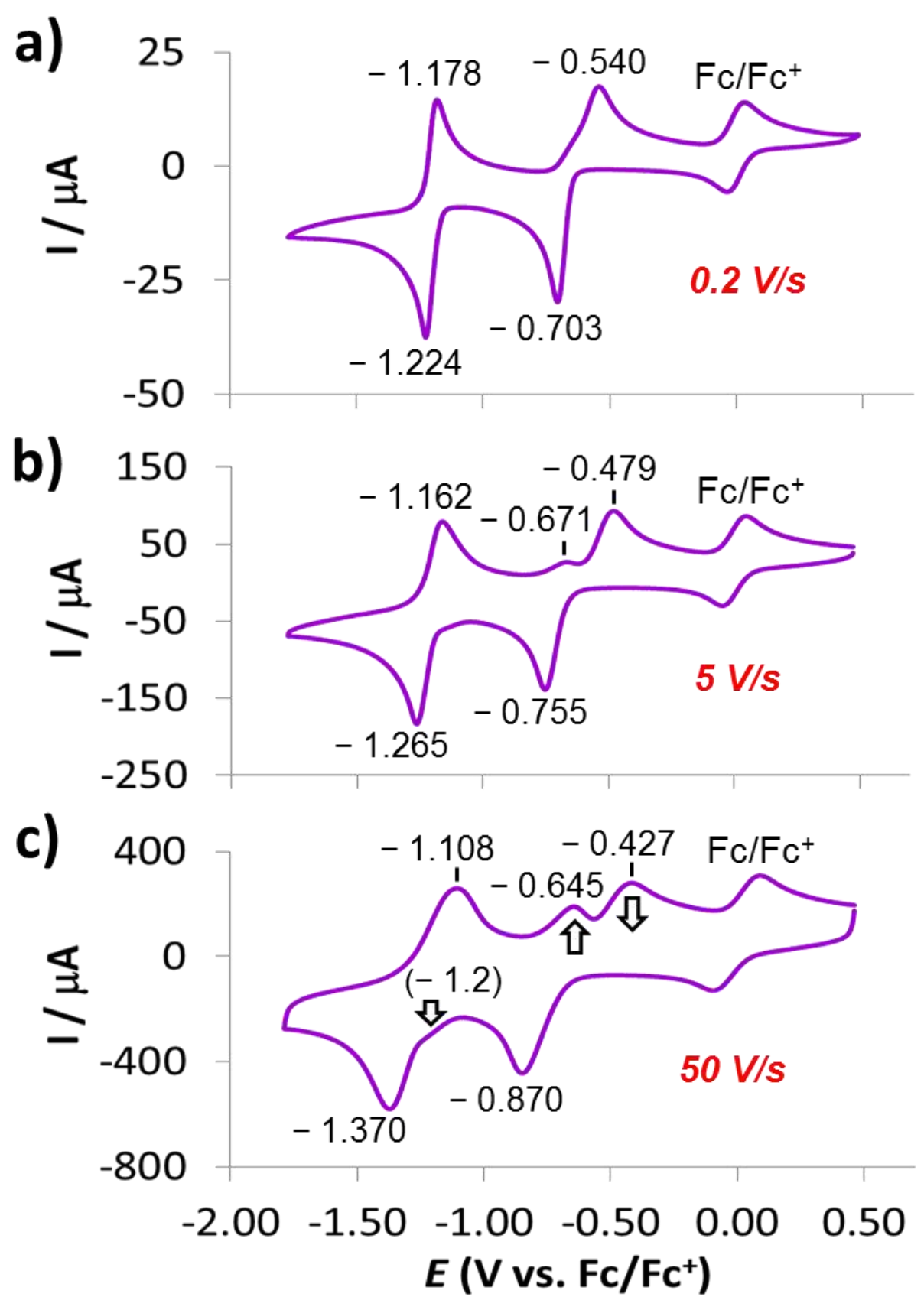

\section{Figure 13}

Cyclic voltammograms of a 1:1 molar ratio mixture of $\mathbf{M S}^{\mathbf{4 +}}$ and $\mathbf{m}-\mathbf{C B P Q T} \mathbf{T}^{\mathbf{4}}(0.2 \mathrm{mM}$ each $)$ in $0.1 \mathrm{M} \mathrm{Bu}_{4} \mathrm{NPF}_{6}$ in $\mathrm{MeCN}$ with potentials referenced to an internal standard of ferrocene $(0.16$ $\mathrm{mM})$. The $\Delta \mathrm{E}_{\mathrm{p}}$ values for the $\mathrm{Fc} / \mathrm{Fc}^{+}$redox couple are: a) $\Delta \mathrm{E}_{\mathrm{p}(\mathrm{Fc} / \mathrm{Fc}+)}=66 \mathrm{mV} / \mathrm{s}$ at $0.2 \mathrm{~V} / \mathrm{s}$. b) $\Delta \mathrm{E}_{\mathrm{p}(\mathrm{Fc} / \mathrm{Fc}+)}=92 \mathrm{mV} / \mathrm{s}$ at $5 \mathrm{~V} / \mathrm{s}$. c) $\Delta \mathrm{E}_{\mathrm{p}\left(\mathrm{Fc} / \mathrm{Fc}^{+}\right)}=185 \mathrm{mV} / \mathrm{s}$ at $50 \mathrm{~V} / \mathrm{s}$. Arrows mark select changes in the $\mathrm{CV}$ recoded at $50 \mathrm{~V} / \mathrm{s}(\mathbf{c})$ relative to the one recorded at $5 \mathrm{~V} / \mathrm{s}(\mathbf{b})$. 


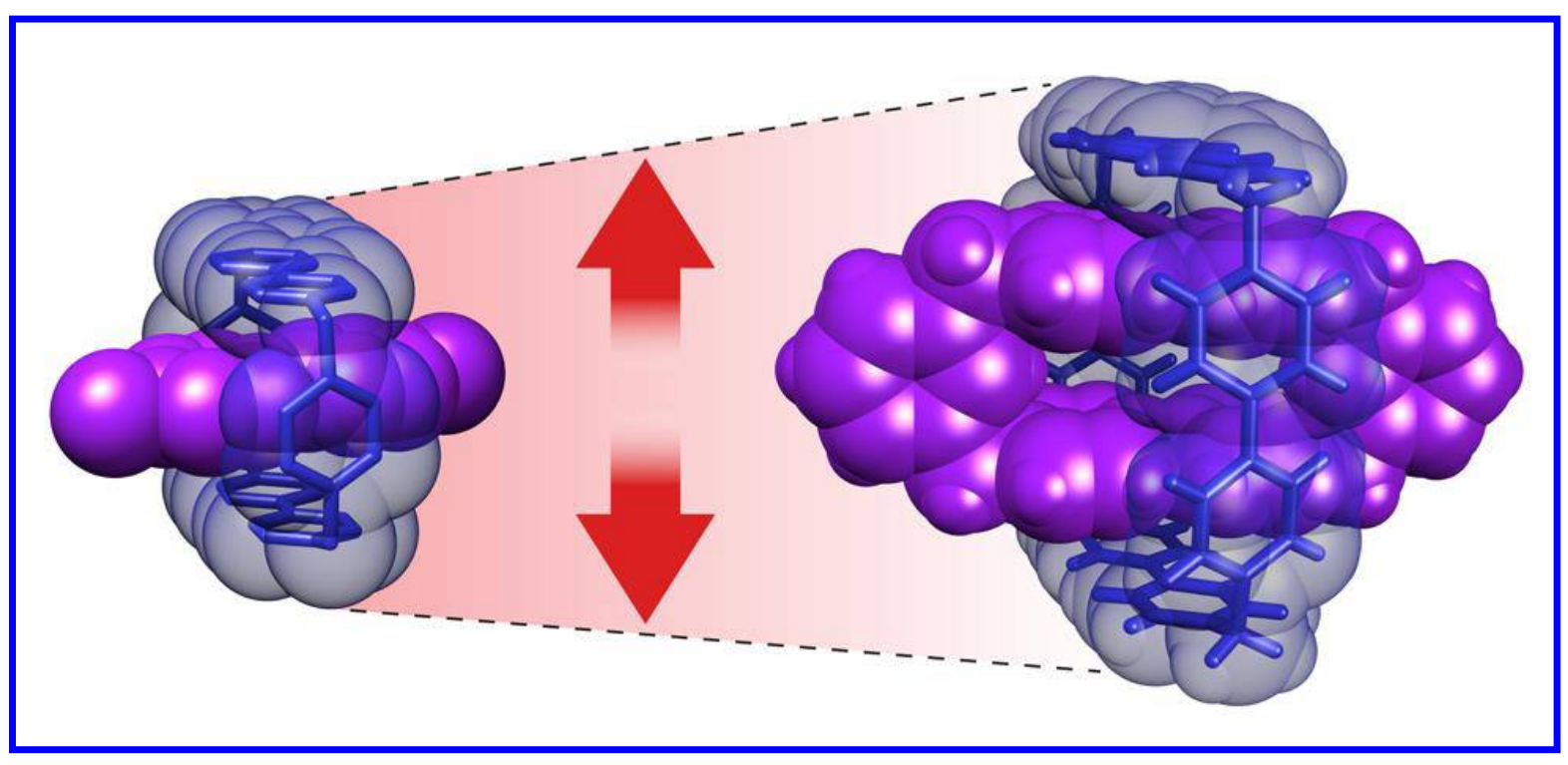

\section{TOC Entry}

27

28 